\author{
JOHN E. CALFEE
}

Brookings Institution

\author{
CLIFFOR D WINSTON
}

Brookings Institution

\title{
The Consumer Welfare Effects of Liability for Pain and Suffering: An Exploratory Analysis
}

A SURGE IN LIABILITY PAYMENTS since the 1960s and periodic crises in the liability insurance market have generated much concern about the products liability system. Indeed, the so-called tort tax, estimated to be in the hundreds of billions of dollars, has been cited as a serious impediment to America's competitiveness. Criticisms of the system have tended to focus on unexpected increases in the size and scope of liability awards, on the inefficiencies inherent in using the liability system as an insurance or compensation mechanism, and on the possible imperfections in the insurance industry itself. ${ }^{1}$

Attention has recently turned to the potential problems caused by awarding nonpecuniary damages-commonly referred to as compensation for pain and suffering. These awards have played a large role in tort payments. Data collected in 1977 indicated that pain and suffering accounted for some 30-57 percent of the amounts awarded by juries in personal injury suits, with these proportions varying according to the nature of the injury. ${ }^{2}$ There is little reason to think this proportion has declined during the past fifteen years of steady increases in tort

The authors are grateful to Ted Miller and to participants at the Brookings Microeconomic Conference for comments, and to Chad Shirley for research assistance. Financial support was provided by the Center for Law, Economics, and Politics at the Brookings Institution.

1. For a discussion of these issues, see Litan and Winston (1988).

2. Viscusi (1991, p. 102). 
payments, increases that have been driven by such developments as liability for defective product design and increased litigation charging sellers with failure to give consumers adequate warning of potential risks. ${ }^{3}$ Moreover, pain and suffering awards would increase far beyond today's levels if courts were to extend the scope of pain and suffering beyond its current boundaries (for example, if courts nationwide were permitted to award damages for wrongful death - something that many states now prohibit).

Awards for pain and suffering may be imposing a substantial deadweight cost on consumers. Consider the following example. Parents who place their child in a position involving risk of death (a summer swimming camp, for example) would pay a substantial amount for a marginal reduction in this risk-say, $\$ 100$ for a reduction of 0.01 percent. But the parents would probably pay very little for insurance against such a risk. They would not choose to reduce their wealth when the child is alive to have more money in the event of the child's death. In the theoretical language of utility analysis, the loss of a child reduces the marginal utility of wealth, so that consumers not only are unlikely to purchase insurance against the event, but, if anything, are likely to prefer "negative"' insurance that permits the parent to have more money when the child is alive and less if the child dies. Thus, for example, a $\$ 1,000,000$ insurance policy against the death of a child in summer camp is worth less than its actuarial value to the parent, and if the parents were forced to purchase such a policy at its actuarial value, most of the cost would be a deadweight loss.

In theory, the liability system has a similar effect on consumers, to the extent that the system imposes strict liability for nonpecuniary losses. ${ }^{4}$ If the loss decreases the marginal utility of wealth, consumers will be willing to pay more for prevention than for insurance. The large willingness to pay for prevention will generate large damage payments. These expected payments will be rolled into the price of the product, in effect serving as an insurance policy for consumers. Continuing the example of the summer camp and assuming the probability of loss to

3. Viscusi (1991, p. 7).

4. In recent years courts have moved toward a strict liability standard, which requires the producer to compensate a victim for all losses caused by the producer's conduct, regardless of the steps a producer has taken to prevent accidents. 
be $0.0001, \$ 100$ of the camp fees would be the implicit insurance premium on a damage award of $\$ 1,000,000$. In competitive markets, the price of the product will be increased to cover this implicit premium for undesired insurance, but because the insurance is worth much less than its actuarial value, most of this price increase will be a burden on consumers. (The overall burden would be larger still, of course, because of the inefficiencies of providing insurance to consumers through product liability litigation.)

It can be argued that market incentives for producers to take precautions are less than optimal in the absence of strict liability for pain and suffering and that the increased incentives associated with such liability could therefore provide a benefit to consumers that would partially or completely offset the burden from overinsurance. We will address the issue of precautionary incentives in future research.

We are unaware of any attempts to address empirically the deadweight loss likely to arise from involuntary insurance associated with damage payments for pain and suffering. ${ }^{5}$ In fact, theoretical disagreement continues about whether overinsurance is likely to be of any significance. ${ }^{6}$ The purpose of this paper is to estimate the potential magnitude of damage payments for pain and suffering and its resulting deadweight loss to consumers and to evaluate briefly some proposals for reforming the product liability system.

\section{Estimating the Burden Caused by Damage Payments for Pain and Suffering}

Nonpecuniary losses (such as death or injury) change the marginal utility of wealth. ${ }^{7}$ One's own death, for example, reduces utility drastically, perhaps to zero (depending on one's valuation of the utility of heirs). Because consumers want insurance to equate marginal utility of wealth after a loss, they are less willing to insure against injuries that reduce marginal utility. Consumers may, however, be willing to pay a great deal to prevent those sorts of injuries. The result is a disparity

5. A recent theoretical treatment of this issue is in Calfee and Rubin (1992).

6. See, for example, Croley and Hanson (1991).

7. This analysis is based on Rubin and Calfee (1992) and sources cited therein. 
between willingness to pay for insurance and willingness to pay for prevention. Because damage payments under strict liability are in effect insurance, a damage payment that is set according to willingness to pay for prevention will generate more than the desired level of insurance, thus mandating involuntary overinsurance. Such insurance would transfer money from situations in which marginal utility of wealth is high to situations in which marginal utility is lower, thus imposing a deadweight burden on consumers. (The situation is different if only pecuniary losses are involved. In that case, consumers are indifferent about avoiding the loss or incurring it and receiving monetary compensation equal to the loss. A strict liability damage payment equal to the loss will therefore generate optimal insurance and optimal precautionary incentives.)

Although pain and suffering damage awards are routinely determined as some multiple of medical expenses, there is no standard legal guideline for calculating these damages. ${ }^{8}$ Recent economic analysis of liability rules, however, suggests a rough convergence on using marginal willingness to pay for preventing pain and suffering as the basis for pain and suffering damages. This measure, equivalent to what has been called "hedonic damages, ", 9 has theoretical appeal because it approximates the penalty necessary to induce individuals and businesses to undertake the optimal level of precautions if the market provides no other precautionary incentives. ${ }^{10}$ Moreover, the evidence available on the relationship between pain and suffering awards and the characteristics of injuries suggests that awards tend to be in the range that would be predicted by the willingness-to-pay criterion. ${ }^{11}$ Under the hedonic damages approach, however, prices will not correctly reflect the risks associated with specific products. ${ }^{12}$ And the market does provide other sources of precautionary incentives, such as manufacturers' reputations. Whether the damage payment increases consumer welfare by improving precautionary incentives therefore depends on the original level of such

8. This multiple can be quite large, commonly estimated at about 2.5 times claimed medical expenses. (See "A Survey of the Legal Profession," The Economist, July 18, 1992, special section, p. 11.)

9. See Viscusi (1988).

10. Shavell (1987, appendix to chap. 10).

11. Miller (1989).

12. Rubin and Calfee (1992). 
incentives. Strict liability for nonpecuniary losses could provide a consumer benefit by moving precautionary incentives closer to the optimal level. If so, this benefit would partially or completely offset the burden from overinsurance.

That burden is the difference between expected payments for damage awards and the value to consumers of these payments as insurance. (We assume that markets are competitive, so that increased insurance costs are reflected in price increases.) Let $M=$ willingness to pay to reduce the probability of injury by the marginal amount $d P$ (for example, $\$ 1,000$ to reduce risk of death by 0.001 ). The damages payment $D$ (based on willingness to pay for prevention) is a linear extrapolation to probability $=1.0$. Hence, $D=M / d P$ (for example, $D=\$ 1,000 /$ $0.001=\$ 1,000,000$ if $M=\$ 1,000)$.

Marginal willingness to pay for prevention obviously depends on the type of injury. For a given injury type $i$, the annual probability of injury is $P_{i}$. One should also take into account the probability that the injurer will actually be held liable; denote this probability by $L_{i}$. Even under strict liability this probability is normally less than 1 because of uncertainty over the cause of the injury.

The expected damage payment $E_{i}$ will be $E_{i}=P_{i} L_{i} D_{i}=P_{i} L_{i} M_{i} / d P_{i}$. Total annual expected payments $T_{i}$ will be expected payments times $N_{i}$, the annual number of injuries expected to fall under liability rules: $T_{i}=N_{i} L_{i} P_{i} D_{i}$.

Let $W=w\left(D_{i}\right)$ denote willingness to pay for an insurance policy that pays $D_{i}$ with probability $P_{i} L_{i}$ in the event of injury of type $i$. When the loss reduces marginal utility (as is conceded to be the case for the most important kinds of injury), ${ }^{13} W_{i}$ will be less than the policy's actuarial value $P_{i} D_{i}$. In many cases, such as some deaths, $W_{i}$ may be small or 0 . Then, for an individual consumer, the burden of overinsurance for injury type $i$ will be $B_{i}=P_{i} L_{i} D_{i}-W_{i}$. Total burden $T B_{i}$ for all consumers will be the individual burden times annual injuries $N_{i}$ :

$$
T B_{i}=N_{i} P_{i} L_{i} D_{i}-N_{i} W_{i}=T_{i}-N_{i} W_{i},
$$

that is, annual burden equals expected payments minus insurance value for all injuries of type $i$. 
To the extent that payments go to victims, this estimate is properly classified as a deadweight loss rather than a transfer, because it necessarily moves wealth from situations of high marginal utility to those with low marginal utility. ${ }^{14}$ The expected residual value of the transaction is reflected in willingness to pay for the involuntary insurance policy. Hence, the difference between the expected payments and the insurance value is a net loss. In contrast, that portion of the payment that goes to plaintiffs' attorneys is a true transfer, although there may be significant efficiency losses in a misallocation of legal talent attracted by the prospect of damage payments for pain and suffering. An additional source of inefficiency, which will not be estimated here, is the increased litigation costs associated with larger damage payments. Again, we ignore the possibility that damage payments for pain and suffering will provide an offsetting consumer benefit by improving precautionary incentives.

\section{Sample and Survey Methods}

This exploratory study focused on some representative products and services and on a mix of victims - either adults ("self") or children. We considered three types of injury: death, permanent disability, and temporary disability. Except for automobiles, no attempt was made to examine products or services for which tort liability has been large. Rather, we sought to explore willingness to pay in connection with a diverse set of situations, some of which could be subject to a significant amount of tort liability in the future.

Table 1 shows the mix of products, injuries, and victims; probabilities; and the annual incidence rates used in later calculations. ${ }^{15}$ For future reference, the table includes the "scenario" number of each sample, with the prevention scenario listed as "a" and the insurance scenario as " $b$. ."

We did not examine many situations in which large tort judgments are now routine. Asbestos, for example, was not included. We also did

14. The utility of payments to heirs or dependents is assumed to be encapsulated in the decisionmaker's utility function. This assumption is consistent with standard willingnessto-pay analyses of economic processes.

15. See appendix A for a full description of the products and services. The questionnaire was administered by Alison-Fisher, Inc., a Southfield, Michigan, marketing consulting firm. 
Table 1. Products, Types of Injury, and Victims

\begin{tabular}{cllllr}
\hline Scenarios & Product & \multicolumn{1}{c}{ Injury } & Victim & Probability & $\begin{array}{r}\text { Annual } \\
\text { events }\end{array}$ \\
\hline 1 a,b & Auto & Death & Self & Implicit & 19,000 \\
2 a,b & Auto & Death & Child & Implicit & 1,919 \\
3 a,b & Auto & Permanent disability & Child & Implicit & 2,335 \\
4 a,b & Medical & Permanent disability & Self & p $=0.01$ & 25,000 \\
5 a,b & Medical & Temporary disability & Self & Implicit & 125,000 \\
6 a,b & Medical & Temporary disability & Child & p =0.001 & 18,203 \\
& & & & (insurance) & \\
& & & & p $=0.0005$ & \\
7 a,b & Drug & Death & Srevention) & \\
8 a,b & Drug & Permanent disability & Child & p $=0.0001$ & 100 \\
9 a,b & Drug & Permanent disability & Child & Implicit & 25 \\
10 a,b & Day & Death & Child & Implicit & 5 \\
& camp & & & & \\
\hline
\end{tabular}

Source: Authors' calculations based on the following data for annual events:

Automobiles: National Highway Transportation Safety Administration, “Federal Accident Reporting System," Database; Department of Commerce, Statistical Abstract of the United States, 1991; Jury Verdict Research, Inc., Horsham, Penn.; Motor Vehicle Manufacturers' Association, MVMA Motor Vehicle Facts and Figures '91, Detroit; National Safety Council, Accident Facts 1992, Itasca, Ill.; American Council of Life Insurance, 1991 Life Insurance Fact Book Update, Washington, D.C.

Drugs: Conversation with Louise Chapman, Influenza Branch, and Dr. Vita Caserta, Vaccine Injury Compensation Program, both of the Centers for Disease Control Information System, Altanta, Ga.; Centers for Disease Control Information System, "Biologics Surveillance Summary, Database."

Medical: Harvard Medical Practice Study (1990), Patients, Doctors, and Lawyers: Medical Injury, Malpractice, Litigation, and Patient Compensation in New York, Cambridge, Mass.; Statistical Abstract of the United States, 1991; California Medical Association (1977), Medical Insurance Feasibility Study, San Francisco.

Day Camp: "Summary Report, Children's Camp-Related Deaths in New York State. 1987-1990," and "'1986 Annual Report, New York State Children's Camp Program," both from New York State Department of Health, Division of Environmental Protection, Albany, N.Y. December 1990; conversation with Diane Danberry, YMCA, Chicago; Statistical Abstract of the United States, $199 \mathrm{I}$

not consider deaths from medical services such as surgery or trauma care. Finally, we did not consider deaths from drugs generally, but only from well-tested vaccines (for which injury rates are very small). Although crude estimates of the willingness to pay for prevention could be obtained from labor market data, such as studies of the value of life, we are unaware of any estimates of the willingness to pay for insurance. ${ }^{16}$ Data from market transactions are unlikely to be available if, as we predict, the value of insurance in many situations is less than its actuarial cost. We therefore designed a survey to generate data to estimate willingness to pay for insurance, and because it is essential to have consistent measures, the survey also generated data to estimate

16. The recent surveys by Viscusi (1990, p. 13) and Priest (1991, p. 247) both note the lack of empirical data on the value of insurance for pain and suffering. 
the willingness to pay for prevention. A sample of 2,020 respondents was drawn from a well-known mail panel whose members were accustomed to preference surveys. Response rates for the twenty scenarios (described below) ranged from 40 to 67 percent approximately three weeks after the mailing, consistent with or slightly better than usual response rates for this panel.

We used established market research techniques to elicit preferences for insurance and prevention in situations that involved possible injury or loss of life to respondents or their children from a product or service. Each situation involved two scenarios that were essentially identical except that one offered prevention and the other offered insurance. To keep questions about prevention from tainting responses about insurance, and vice versa, separate samples were drawn for each scenario. A few situations provided respondents with an explicit probability of injury; in most situations, probability was left unstated to make the choice as natural as possible and to allow us to learn something of respondents' assumptions about injury rates. Respondents were confronted with eight to thirteen alternatives, or " packages," each on a separate card that included the price and other attributes of the product or service, plus an insurance policy (or a prevention option). From previous surveys they had completed, the respondents were familiar with choice objects of similar or greater complexity and with a similar number of packages. The individuals were asked to rate the alternatives on a 1-to-10 scale of willingness to purchase. Respondents were then asked to rank the cards from most to least preferred, thus providing an opportunity to resolve ties among equally rated alternatives. Some of the alternatives "dominated" others, that is, some provided the same package at a lower price. These alternatives allowed the rating scheme to reflect trade-offs between prices and attributes. Market research professionals aided in the design of stimuli and administered both the pretests and the final survey. Extensive pretesting of selected scenarios included both in-house and field tests and continued until subjects were comfortable with the task and provided results that conformed to intuition.

As an illustration, exhibit 1 presents scenarios $1 \mathrm{a}$ and $1 \mathrm{~b}$ and the choices that respondents faced (the remaining scenarios are in appendix A). Screening questions eliminated respondents for whom the scenarios would not be relevant. The automobile scenarios involved respondents 


\section{Exhibit 1. Scenario 1a}

Suppose you need to buy a car. After 2 weeks of looking, you have decided which model to buy. You still have to decide on the following items:

Price: The price of the automobile varies depending on the items contained in the package.

Engine Size: A larger engine is offered. It gets you slightly worse fuel economy than the standard engine, but makes the car accelerate from " 0 " to " 60 " miles an hour in 10 seconds instead of 13 seconds for the standard engine.

Safety Package: The safety package cuts in half the chances of the driver having a fatal accident (assume you will be driving the car).

Air Conditioning: Air conditioning is an option.

Note: There is NO difference in quality other than differences in the items contained in the package. Remember, the model of car is the same for each package except for the items mentioned in the package.

\begin{tabular}{ccccc}
\hline Package & Price & Engine size & Safety package & Air conditioner \\
\hline 1 & $\$ 10,000$ & Small & No & No \\
2 & 10,200 & Small & Yes & No \\
3 & 10,500 & Small & Yes & No \\
4 & 11,000 & Small & No & Yes \\
5 & 11,800 & Small & Yes & Yes \\
6 & 11,000 & Large & No & No \\
7 & 11,400 & Large & Yes & No \\
8 & 12,000 & Large & Yes & No \\
9 & 12,000 & Large & No & Yes \\
10 & 12,050 & Large & Yes & Yes \\
11 & 12,500 & Large & Yes & Yes \\
12 & 13,000 & Large & Yes & Yes \\
13 & 13,500 & Large & Yes & Yes \\
\hline
\end{tabular}

who owned automobiles and were of driving age. Scenarios involving children sampled only families with children of the appropriate age. Childbirth scenarios used female respondents of child-bearing age who had already had children. Respondents to scenarios involving day camps or injuries to themselves were screened to ensure household incomes of at least $\$ 40,000$.

Estimates of the implicit willingness to pay for insurance and prevention were obtained from the parameters that represented the influence of the various attributes on the ordering of alternatives. The statistical technique, described below, was ordered probit. 


\section{Exhibit 1. Scenario 1b}

Suppose you need to buy a car. After 2 weeks of looking, you have decided which model to buy. You still have to decide on the following items:

Price: The price of the automobile varies depending on the items contained in the package.

Engine Size: A large engine is offered. It gets slightly worse fuel economy than the standard engine, but the car accelerates from " 0 " to " 60 " miles an hour in 10 seconds instead of 13 seconds for the standard small engine.

Insurance Policy: The insurance policy would pay money to your family (or designated beneficiary) if you have a fatal accident while driving the car. This money would be in addition to whatever life insurance you already have (assume you will be driving the car).

Air Conditioning: Air conditioning is an option.

Note: There is NO difference in quality other than differences in the items contained in the package. Remember, the model of car is the same for each package except for the items mentioned in the package.

\begin{tabular}{|c|c|c|c|c|}
\hline Package & Price & $\begin{array}{l}\text { Engine } \\
\text { size }\end{array}$ & $\begin{array}{c}\text { Insurance } \\
\text { payout }\end{array}$ & $\begin{array}{c}\text { Air } \\
\text { conditioner }\end{array}$ \\
\hline 1 & $\$ 10,000$ & Small & 0 & No \\
\hline 2 & 10,100 & Small & 10,000 & No \\
\hline 3 & 10,300 & Small & 500,000 & No \\
\hline 4 & 11,000 & Small & 0 & Yes \\
\hline 5 & 11,500 & Small & 100,000 & Yes \\
\hline 6 & 10,000 & Large & 0 & No \\
\hline 7 & 10,100 & Large & 50,000 & No \\
\hline 8 & 11,000 & Large & 100,000 & No \\
\hline 9 & 12,000 & Large & 0 & Yes \\
\hline 10 & 12,075 & Large & 100,000 & Yes \\
\hline 11 & 12,200 & Large & 200,000 & Yes \\
\hline 12 & 12,500 & Large & 500,000 & Yes \\
\hline 13 & 13,500 & Large & $1,000,000$ & Yes \\
\hline
\end{tabular}

Our approach to estimating willingness to pay is a form of contingent valuation. Our method, however, differs sharply from much previous work, which has been criticized on several grounds as generating unreliable estimates and as departing from methods favored in the market research discipline. The bulk of these criticisms of contingent valuation do not apply to our approach. ${ }^{17}$

17. Biases are claimed to arise using contingent valuation because people are asked to value something they are not familiar with, because the value of a commodity or service is sensitive to its position in a sequence of questions, because people are not forced to 


\section{Estimation Results}

For statistical analysis, we used ordered probit, a maximum likelihood procedure that assumes utility-maximizing choice behavior and takes into account the full ranking information available from each respondent. Rankings are assumed to reflect an unobserved, continuous utility function of product price and attributes, plus a normally distributed error term. Thus, an observed ranking of 3, for example, would arise when the unobserved variable plus error term takes a value between 3 and 4.

Ordered probit estimates a utility function in which the coefficient for each influence (price, insurance or prevention, and other attributes) indicates the sensitivity of utility to a change in the attribute. The ratios of coefficients provide estimates of trade-offs. For example, the ratio of the coefficient for prevention to the coefficient for price represents willingness to pay for prevention. Data for respondents facing identical choices were combined to estimate a single utility function. We assumed that errors were uncorrelated across respondents. Informal tests of this assumption (based on estimation from small subsamples) indicated that it did not materially affect parameter estimates.

Table 2 presents the ordered probit parameter estimates of the price, insurance, and prevention variables for each scenario and forms the ratio of these parameters to calculate the implied willingness to pay for prevention and for insurance. The probability is that associated with the product and situation, for example, the likelihood of death for a driver in connection with an automobile that is purchased new and is kept for whatever time the respondent typically expected when contemplating a purchase.

Each of the twenty scenarios had coefficients for price and either risk reduction (prevention) or insurance. Generally, these coefficients had the expected sign and were statistically reliable. ${ }^{18}$ The high statistical reliability was not guaranteed by the survey format; coefficients

make commitments and thus they behave as if they have no budget constraint, and because individuals tend to give the response they perceive to be appropriate.

18. Respondents were asked to rank packages, with the most favored package ranked number 1 , and so on. The expected sign for price was therefore positive (because higher prices bring worse rankings), and the expected signs for insurance and prevention were negative. Willingness-to-pay calculations reverse these signs, so that willingness to pay is positive. 


\begin{tabular}{|c|c|c|c|c|c|}
\hline Scenario & $\begin{array}{l}\text { Coefficient }^{a} \\
(t \text {-statistic) }\end{array}$ & $\begin{array}{l}\text { Willingness } \\
\text { to pay to } \\
\text { reduce risk }\end{array}$ & $\begin{array}{c}\text { Value of } \\
\text { prevention }\end{array}$ & $\begin{array}{l}\text { Willingness } \\
\text { to pay for } \\
\text { insurance }^{d}\end{array}$ & $\begin{array}{l}\text { Actuarial } \\
\text { value of } \\
\text { insurance }^{e}\end{array}$ \\
\hline \multicolumn{6}{|c|}{ 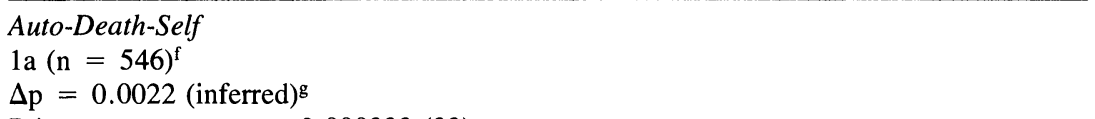 } \\
\hline Price & $0.000333(33)$ & 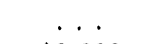 & & $\ldots$ & $\ldots$ \\
\hline Less risk $^{\mathrm{h}}$ & $-1.30(13)$ & $\$ 3,900$ & $\$ 1,772,000$ & $\cdots$ & $\cdots$ \\
\hline \multicolumn{6}{|c|}{$\begin{array}{l}1 b(n=481): \\
p=0.0044 \text { (inferred) }\end{array}$} \\
\hline Price & $0.000191(22)$ & $\ldots$ & . . & . . & $\ldots$ \\
\hline$\$ 100,000$ insurance & $-0.0603(3.5)$ & $\cdots$ & $\cdots$ & $\$ 316$ & $\$ 440$ \\
\hline \multicolumn{6}{|c|}{$\begin{array}{l}2 \mathrm{a}(\mathrm{n}=611) \\
\Delta \mathrm{p}=0.00306 \text { (inferred) }\end{array}$} \\
\hline Price & $0.000297(31)$ & . & . & $\ldots$ & $\ldots$ \\
\hline Less risk & $-1.36(14)$ & 4,579 & $1,500,000$ & $\cdots$ & $\cdots$ \\
\hline \multicolumn{6}{|c|}{$2 b(n=546)$} \\
\hline Price & $0.000213(26)$ & $\ldots$ & $\ldots$ & . . & $\ldots$ \\
\hline$\$ 100,000$ insurance & $-0.0287(1.8)$ & $\cdots$ & $\cdots$ & 135 & 611 \\
\hline $\begin{array}{l}\text { Auto-Perm.-Child } \\
3 \mathrm{a}(\mathrm{n}=559) \\
\Delta \mathrm{p}=0.0039 \text { (inferr }\end{array}$ & ed) & & & & \\
\hline $\begin{array}{l}\text { Price } \\
\text { Less risk }\end{array}$ & $\begin{aligned} & 0.000301(30) \\
- & 1.47(15)\end{aligned}$ & $\ddot{4,804}$ & $1,240,000$ & $\begin{array}{l}\cdots \\
\cdots\end{array}$ & $\begin{array}{l}\cdots \\
\cdots\end{array}$ \\
\hline \multicolumn{6}{|l|}{$3 b(n=520)$} \\
\hline Price & $0.000180(21)$ & $\cdots$ & . . & $\cdots$ & $\cdots$ \\
\hline$\$ 100,000$ insurance & $-0.0394(2.4)$ & $\cdots$ & $\cdots$ & 219 & 775 \\
\hline $\begin{array}{l}\text { Medical-Perm.-Self } \\
4 \mathrm{a}(\mathrm{n}=368) \\
\mathrm{p}=0.01 \text { (explicit) }\end{array}$ & & & & & \\
\hline Price & $0.00947(5.3)$ & 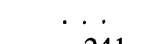 & & $\cdots$ & $\cdots$ \\
\hline $\begin{array}{l}\text { No side effects } \\
4 \mathrm{~b}(\mathrm{n}=360) \\
\mathrm{p}=0.01 \text { (explicit) }\end{array}$ & $-0.228(1.8)$ & 241 & 24,100 & 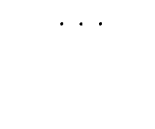 & $\ldots$ \\
\hline $\begin{array}{l}\text { Price } \\
\$ 100,000 \text { insurance }\end{array}$ & $\begin{aligned} & 0.00190(5.5) \\
- & 1.77(4.7)\end{aligned}$ & $\begin{array}{l}\cdots \\
\cdots\end{array}$ & $\begin{array}{l}\cdots \\
\cdots\end{array}$ & $\cdots 98$ & $\ddot{1,000}$ \\
\hline
\end{tabular}


Table 2. (continued)

\begin{tabular}{|c|c|c|c|c|c|}
\hline Scenario & $\begin{array}{l}\text { Coefficient }^{a} \\
\text { (t-statistic) }\end{array}$ & $\begin{array}{l}\text { Willingness } \\
\text { to pay to } \\
\text { reduce risk }\end{array}$ & $\begin{array}{c}\text { Value of } \\
\text { prevention }\end{array}$ & $\begin{array}{l}\text { Willingness } \\
\text { to pay for } \\
\text { insurance }^{d}\end{array}$ & $\begin{array}{l}\text { Actuarial } \\
\text { value of } \\
\text { insurance }^{e}\end{array}$ \\
\hline \multicolumn{6}{|l|}{$\begin{array}{l}\text { Medical-Temp.-Self } \\
5 \mathrm{a}(\mathrm{n}=456) \\
\mathrm{p}=0.0179 \text { (inferred) }\end{array}$} \\
\hline $\begin{array}{l}\text { Price } \\
\text { No side effects }\end{array}$ & $\begin{array}{l}0.00141(8.7) \\
-0.253(2.2)\end{array}$ & 179 & 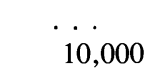 & $\begin{array}{l}\cdots \\
\cdots\end{array}$ & $\begin{array}{l}\cdots \\
\cdots\end{array}$ \\
\hline \multicolumn{6}{|l|}{$5 b(n=352)$} \\
\hline $\begin{array}{l}\text { Price } \\
\$ 100,000 \text { insurance }\end{array}$ & $\begin{array}{c}0.00157(4.5) \\
-0.0777(2.0)\end{array}$ & $\begin{array}{l}\cdots \\
\cdots\end{array}$ & $\begin{array}{l}\cdots \\
\cdots\end{array}$ & $\cdots$ & 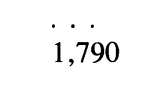 \\
\hline \multicolumn{6}{|c|}{$\begin{array}{l}6 \mathrm{a}(\mathrm{n}=650) \\
\Delta \text { prob. }=0.0005 \text { (explicit) }\end{array}$} \\
\hline $\begin{array}{l}\text { Price } \\
\text { Less risk }\end{array}$ & $\begin{array}{l}0.00493(8.4) \\
-0.545(5.4)\end{array}$ & $\cdots$ & 222,000 & $\begin{array}{l}\cdots \\
\cdots\end{array}$ & $\begin{array}{l}\cdots \\
\cdots\end{array}$ \\
\hline \multicolumn{6}{|l|}{$6 b(n=520)$} \\
\hline $\begin{array}{l}\text { Price } \\
\$ 100,000 \text { insurance }\end{array}$ & $\begin{array}{l}0.00703(7.4) \\
-0.401(3.4)\end{array}$ & $\begin{array}{l}\cdots \\
\cdots\end{array}$ & $\begin{array}{l}\cdots \\
\cdots\end{array}$ & $\cdots$ & 100 \\
\hline $\begin{array}{l}\text { Drug-Death-Self } \\
7 \mathrm{a}(\mathrm{n}=490) \\
\Delta \mathrm{p} .=0.00005(\exp \end{array}$ & licit) & & & & \\
\hline $\begin{array}{l}\text { Price } \\
\text { Vaccine }\end{array}$ & $\begin{aligned} & 0.0387(11) \\
- & 3.43(9.1)\end{aligned}$ & . & $1,772,000$ & $\begin{array}{l}\cdots \\
\cdots\end{array}$ & $\cdots$ \\
\hline \multicolumn{6}{|c|}{$7 \mathrm{~b}(\mathrm{n}=741)$} \\
\hline $\begin{array}{l}\text { Price } \\
\$ 100,000 \text { insurance }\end{array}$ & $\begin{array}{r}0.130(20) \\
-0.718(21)\end{array}$ & $\begin{array}{l}\cdots \\
\cdots\end{array}$ & $\begin{array}{l}\cdots \\
\cdots\end{array}$ & 5.52 & $\cdots$ \\
\hline $\begin{array}{l}\text { Drug-Perm.-Child } \\
8 \mathrm{a}(\mathrm{n}=550) \\
\mathrm{p}=0.0001 \text { (explici }\end{array}$ & & & & & \\
\hline $\begin{array}{l}\text { Price } \\
\text { Eliminate risk }\end{array}$ & $\begin{aligned} & 0.00258(1.17) \\
- & 0.320(2.3)\end{aligned}$ & $\cdots$ & $1,240,000$ & $\cdots$ & $\cdots$ \\
\hline \multicolumn{6}{|l|}{$8 b(n=689)$} \\
\hline $\begin{array}{l}\text { Price } \\
\$ 100,000 \text { insurance }\end{array}$ & $\begin{aligned} & 0.00853(17) \\
- & 0.888(17)\end{aligned}$ & $\begin{array}{l}\cdots \\
\cdots\end{array}$ & $\begin{array}{l}\cdots \\
\cdots\end{array}$ & 10.40 & $\cdots$ \\
\hline
\end{tabular}


Table 2. (continued)

\begin{tabular}{|c|c|c|c|c|c|}
\hline Scenario & $\begin{array}{l}\text { Coefficient }^{a} \\
\text { (t-statistic) }\end{array}$ & $\begin{array}{l}\text { Willingness } \\
\text { to pay to } \\
\text { reduce risk }\end{array}$ & $\begin{array}{c}\text { Value of } \\
\text { prevention }^{c}\end{array}$ & $\begin{array}{l}\text { Willingness } \\
\text { to pay for } \\
\text { insurance }^{d}\end{array}$ & $\begin{array}{c}\text { Actuarial } \\
\text { value of } \\
\text { insurance }\end{array}$ \\
\hline \multicolumn{6}{|c|}{ Drug-Perm.-Child (continued) } \\
\hline \multicolumn{6}{|c|}{$9 \mathrm{a}(\mathrm{n}=650)$} \\
\hline \multicolumn{6}{|c|}{ p. $=0.0000637$ (inferred) } \\
\hline Price & $0.00403(1.54)$ & & & $\ldots$ & $\ldots$ \\
\hline Eliminate risk & $-0.320(2.3)$ & 79 & $1,240,000$ & $\ldots$ & $\ldots$ \\
\hline \multicolumn{6}{|l|}{$9 b(n=650)$} \\
\hline \multicolumn{6}{|c|}{$\mathrm{p}=0.0000637$ (inferred) } \\
\hline Price & $0.0420(15)$ & $\ldots$ & . & & \\
\hline$\$ 100,000$ insurance & $-0.115(10)$ & $\cdots$ & . & 2.70 & 6.37 \\
\hline \multicolumn{6}{|c|}{ Day Camp-Death-Child } \\
\hline \multicolumn{6}{|c|}{$10 \mathrm{a}(\mathrm{n}=512)$} \\
\hline \multicolumn{6}{|c|}{$\Delta \mathrm{p}=0.00036$ (inferred) } \\
\hline Price & $0.00219(8.1)$ & & & . & \\
\hline Less risk & $-1.17(9.6)$ & 535 & $1,500,000$ & $\ldots$ & \\
\hline \multicolumn{6}{|l|}{$10 \mathrm{~b}(\mathrm{n}=480)$} \\
\hline \multicolumn{6}{|c|}{ red) } \\
\hline Price & $0.0000325(0.12)$ & & & & \\
\hline$\$ 100,000$ insurance & $0.000919(5.6)$ & & & $\mathrm{i}$ & $\mathrm{i}$ \\
\hline
\end{tabular}

Source: Authors' calculations.

a. Positive coefficients indicate undesirable attributes and vice versa.

b. Risk coefficient divided by price coefficient (sign reversed).

c. Willingness to pay to reduce risk (sign reversed), divided by probability when probability is explicit; for inferred probability, value of prevention is assumed (see text).

d. Insurance coefficient divided by price coefficient (sign reversed).

e. Probability times $\$ 100,000$.

f. $n=$ (number of respondents) times (number of packages per respondent).

g. If not explicit, probability is calculated in prevention scenario as willingness to pay to reduce risk divided by value of prevention. This calculated value is used in insurance scenarios and is doubled in cases where prevention involved eliminating only half the risk of injury.

h. "Less risk" involved eliminating half the risk of injury.

i. Could not be determined.

for other attributes such as engine size in autos or fewer shots in medical procedures (reported in appendix B and discussed below) were often of marginal significance or less.

Scenario 1 provides representative calculations. In scenario $1 \mathrm{a}$, the ratio of the "less risk" and price coefficients indicates that respondents were willing to pay $\$ 3,900$ to eliminate half the risk of a driver dying in an automobile that had been bought new. ${ }^{19}$ The value of prevention

19. This finding is consistent with Winston and Mannering's (1984) estimate of the willingness to pay for automobile safety. 
(in this case, "value of life") is taken from scenario 7a, where an explicit probability of injury allowed a direct calculation of the value of prevention. ${ }^{20}$ The inferred (perceived) reduction in probability of injury is calculated as the willingness to pay to reduce risk divided by the value of prevention, yielding a value of 0.0022 . Thus, respondents, who were asked about eliminating half the risk of death, perceived the probability of death as 0.0044 , or approximately 1 in 227 during the course of the five years or so in which the typical new car is kept. ${ }^{21}$

In scenario $1 \mathrm{~b}$, the ratio of the insurance and price coefficients yielded an estimated willingness to pay of $\$ 316$ for $\$ 100,000$ in life insurance in the same situation. Because the probability inferred in scenario 1a represented half the perceived risk of death, twice this probability, or 0.0044 , was used for the implicit probability in scenario $1 \mathrm{~b}$. This prob-

20. Scenarios with explicit probabilities allowed a direct estimate of both the value of prevention and the value of insurance. The estimated values of prevention were generally reasonable, except in scenario 4 , which, as explained in the text, did not offer the opportunity to pay large amounts for prevention. In scenarios with nonmarginal explicit probabilities (scenarios 4 and 6), willingness to pay for insurance was, as predicted, less than willingness to pay for prevention. In scenarios 7 and 8 , which had very small explicit probabilities, respondents were willing to pay actuarial values of insurance. But the implicit insurance premiums were small in these scenarios, only $\$ 5$ or $\$ 10$ for $\$ 100,000$ insurance policies. As discussed in the text, we would not expect this willingness to pay for insurance to increase linearly for situations where probabilities of larger injury translate into much larger implicit insurance premiums for expected liability payments. Rather, because of income effects, consumer willingness to pay for insurance would increase less than proportionately with insurance payouts. In scenarios with implicit probabilities, we could take either a value of prevention or a value of insurance from explicit probability scenarios. For the reasons just explained, we used values of prevention from the scenarios with very small explicit probabilities, but we did not extrapolate linearly from the value of insurance in those scenarios. To do so would have resulted in absurd conclusions. Had we extrapolated the value of insurance from scenario 7 for use in scenario 1, for example, we would have had to assume that consumers would be willing to pay $\$ 7,800$ extra for a $\$ 1,772,000$ life insurance policy bundled with a new automobile. This is clearly unreasonable. Instead, we took the values of prevention from scenarios with explicit probabilities, used these to infer subjective probabilities in scenarios without explicit probabilities, and used the inferred probabilities to calculate the actuarial value of insurance, which was then compared to estimated willingness to pay for insurance. As noted, because of income effects, the value of insurance we used in this approach was still likely to be an overestimate of willingness to pay for insurance.

21. Assuming that 20,000 drivers are killed annually and that about one-fifth of these are driving 1 of the $10,000,000$ new vehicles sold each year, the probability per vehicle is 0.0004 , or about 0.002 over five years, which is 1 in 500 . The respondents' perceived probability of 1 in 227 therefore suggests that they had a reasonable view of the risks involved in driving. 
ability was used to calculate the actuarial value of $\$ 440$ for $\$ 100,000$ in insurance. Thus, we find that respondents valued the "involuntary", insurance at less than its actuarial value in situations involving the possibility of a fatal automobile accident.

Similar calculations were performed for the other scenarios. Explicit probabilities (in scenarios 4, 6, 7, and 8) permitted direct calculations of willingness to pay for prevention. These values are roughly consistent with value-of-life estimates based on market data. Respondents in scenario $7 \mathrm{a}$ were willing to pay $\$ 89$ to reduce the probability of death by 0.00005 , which translates into a value of life of $\$ 1,772,000$. In scenario $8 \mathrm{a}$, willingness to pay to eliminate a 0.0001 risk of permanent disability in a child was $\$ 124$, translating into $\$ 1,240,000$ as the value of a life without such a disability. These values were used in other scenarios (such as 1a, already described) to calculate "inferred," or perceived, probabilities. In the case of death of a child, we used a value of prevention of $\$ 1,500,000$, which is more than the value of prevention for permanent disability (in scenario $8 \mathrm{a}$ ) but less than the $\$ 1,772,000$ value of life for adult respondents. The value of prevention in scenario 5a, which involved a disability of only three months due to headaches and nausea, was arbitrarily chosen to be $\$ 10,000$.

Perceived probabilities had orders of magnitudes that varied appropriately across product categories. Perceived probability of death during the lifetime of a new car, for example, was on the order of 1 in 250 for drivers or children. This is reasonable. Perceived probability of death for a child in day camp, on the other hand, was only 1 in 1,500, and perceived probability of death from a child vaccine was about 1 in 15,000. Although these are, appropriately, far lower than the probability in the auto death scenarios, they undoubtedly are much higher than actual probabilities.

The least satisfactory estimates were for scenario $10 \mathrm{~b}$, in which the price coefficient was extremely unreliable and the insurance coefficient was of the wrong sign, as if more insurance made alternatives less attractive. This may have been because of an unduly high correlation between price and insurance in the packages presented to respondents. Scenario 10a showed the expected high willingness to pay to reduce risk, but the insignificant price coefficient in $10 \mathrm{~b}$ precluded an estimate of the actuarial value of insurance.

Scenario 4 a presented a different problem. The explicit probability 
of permanent disability (resulting from an emergency operation for a head wound) was the relatively high value of 0.01 . Inspection of the survey results showed that respondents were eager to pay to eliminate such a risk, but the array of prices precluded a revealed value of prevention much larger than the calculated value of $\$ 24,100$. The results in scenario $4 \mathrm{~b}$, showing a relatively low value of insurance, appear to be more valid.

The striking finding from these estimations is the wide variation in the value of insurance. In the automobile and medical scenarios, insurance is consistently valued at less than its actuarial value, suggesting the potential for significant deadweight losses from insurance induced by liability for pain and suffering. As predicted by theory, the discrepancy between willingness to pay for prevention and willingness to pay for insurance is greater for children than for adult respondents. In the drug scenarios, the insurance was valued at close to its actuarial value, suggesting the absence of a deadweight loss. A determination could not be made for the day camp scenario.

These results reflect the demographic mix of the sample of respondents. To be sure, willingness to pay can be expected to vary with various demographics. But demographic variables were not included in the statistical analysis because they are fixed characteristics of decisionmakers rather than attributes of the objects of choice. The exclusion of demographics does not lead to bias in our results; rather, for each sample, our results represent average willingness to pay. We note that one could estimate, for example, the relationship between income and willingness to pay in our samples and use this relationship to predict willingness to pay for different demographic groups.

Estimation results for attribute parameters other than prevention and insurance are presented in appendix B. Most were reasonable. Respondents in the first six scenarios (numbers 1 a through $3 b$ ) were consistently willing to pay a great deal (often, several thousand dollars) for automobile air conditioning, which presumably reflects substantial consumer surplus associated with these purchases. Parameter estimates for a larger engine in these same scenarios were of mixed signs and usually insignificant-a reasonable result given that some consumers might attach negative value to larger, less fuel-efficient engines. To our surprise, scenarios $4 \mathrm{a}, 4 \mathrm{~b}, 5 \mathrm{a}$, and $5 \mathrm{~b}$ all yielded insignificant estimates for willingness to pay for fewer shots. This may reflect the 
relative unimportance of this product attribute in the face of the serious health consequences described in these scenarios. Roughly the same comment applies to scenarios $6 \mathrm{a}$ and $6 \mathrm{~b}$, involving less pain and shorter labor in childbirth. Scenarios 7, 8, and 9 all presented similar patterns of anomalous results: prevention scenarios (7a, 8a, 9a) all provided statistically significant incorrect signs for less pain and fewer shots, whereas the estimates in the insurance scenarios $(7 b, 8 b, 9 b)$ werewith one exception-statistically significant with the correct sign. The reasons for this are unclear. Finally, scenarios $10 \mathrm{a}$ and $10 \mathrm{~b}$ yielded the expected positive signs for fewer children per counselor. Thus, results for seventeen of the twenty scenarios were reasonable for almost every parameter for each of three or four product attributes (including price and prevention or insurance).

It is encouraging that the survey methods were robust in several respects. Parallel scenarios produced similar parameter estimates for identical attributes such as price and engine size. At the same time, variations in other parameter estimates yielded a high willingness to pay for some attributes (for example, automobile air conditioning or fewer children per camp counselor) but not for some others. Finally, survey respondents who were given no probability at all as a guide (other than the word "rare" in one or two scenarios) acted as if they had in mind probabilities whose orders of magnitude varied in appropriate ways. When probabilities were explicit, willingness to pay for prevention varied in reasonable ways as probabilities ranged from 0.01 to 0.00005 .

\section{Estimates of Consumer Burden from Overinsurance}

Table 3 presents estimates of the consumer burden from overinsurance associated with liability for pain and suffering in the various scenarios. We assumed that damage payments for pain and suffering would be set at the value of prevention (that is, hedonic damages). The annual number of events potentially subject to liability was taken from table 1. We used public sources to estimate the probability that firms (including consumer insurance carriers) would be held liable for these events. These probabilities reflect the likelihood that the liability system 
Table 3. Annual Burden from Liability for Pain and Suffering

\begin{tabular}{|c|c|c|c|c|c|c|}
\hline Scenario & $\begin{array}{l}\text { Individual } \\
\text { value of } \\
\text { prevention } \\
\text { (thousands) }^{a}\end{array}$ & $\begin{array}{l}\text { Annual } \\
\text { events }^{b}\end{array}$ & $\begin{array}{l}\text { Probability } \\
\text { of liability }^{c}\end{array}$ & $\begin{array}{c}\text { Total } \\
\text { implicit } \\
\text { insurance } \\
\text { (millions) }^{d}\end{array}$ & $\begin{array}{c}\text { Total } \\
\text { value of } \\
\text { insurance } \\
\text { (millions) }^{e}\end{array}$ & $\begin{array}{c}\text { Total } \\
\text { annual } \\
\text { burden } \\
\text { (millions) }\end{array}$ \\
\hline \multicolumn{7}{|l|}{ Autos } \\
\hline 1. Death-self & $\begin{array}{r}\$ 1,000 \\
1,772 \\
2,000\end{array}$ & $\begin{array}{l}19,000 \\
19,000 \\
19,000\end{array}$ & $\begin{array}{l}0.50 \\
0.50 \\
0.50\end{array}$ & $\begin{array}{r}\$ 9,500 \\
16,834 \\
19,000\end{array}$ & $\begin{array}{r}\$ 3,849 \\
12,090 \\
15,395\end{array}$ & $\begin{array}{r}\$ 5,651 \\
4,744 \\
3,605\end{array}$ \\
\hline 2. Death-child & $\begin{array}{l}1,000 \\
1,500 \\
2,000\end{array}$ & $\begin{array}{l}1,919 \\
1,919 \\
1,919\end{array}$ & $\begin{array}{l}0.50 \\
0.50 \\
0.50\end{array}$ & $\begin{array}{r}960 \\
1,439 \\
1,919\end{array}$ & $\begin{array}{l}141 \\
318 \\
566\end{array}$ & $\begin{array}{r}818 \\
1,212 \\
1,353\end{array}$ \\
\hline 3. Perm.-child & $\begin{array}{l}1,000 \\
1,240 \\
2,000\end{array}$ & $\begin{array}{l}2,335 \\
2,335 \\
2,335\end{array}$ & $\begin{array}{l}0.50 \\
0.50 \\
0.50\end{array}$ & $\begin{array}{l}1,168 \\
1,448 \\
2,335\end{array}$ & $\begin{array}{r}266 \\
409 \\
1,064\end{array}$ & $\begin{array}{r}901 \\
1,039 \\
1,271\end{array}$ \\
\hline
\end{tabular}

\section{Medical}

$\begin{array}{lrrrrrr}\text { 4. Perm.-self } & 24,000 & 25,000 & 0.015 & 9 & 1 & 8 \\ \text { 5. Temp.-self } & 5 & 125,000 & 0.015 & 9 & 0.1 & 9 \\ & 10 & 125,000 & 0.015 & 19 & 0.5 & 18 \\ & 15 & 125,000 & 0.015 & 28 & 1.2 & 27 \\ \text { 6. Temp.-child } & 222 & 18,203 & 0.04 & 162 & 92 & 70\end{array}$

\section{Drug}

$\begin{array}{lrrrrrr}\text { 7. Death-self } & 1,772 & 100 & 0.50 & 87 & 87 & 0 \\ \text { 8. Perm.-child } & 1,240 & 100 & 0.50 & 62 & 62 & 0 \\ \text { 9. Perm.-child } & 1,000 & 25 & 0.50 & 13 & 5 & 8 \\ & 1,240 & 25 & 0.50 & 16 & 7 & 9 \\ & 2,000 & 25 & 0.50 & 25 & 17 & 8\end{array}$

\section{Day camp}

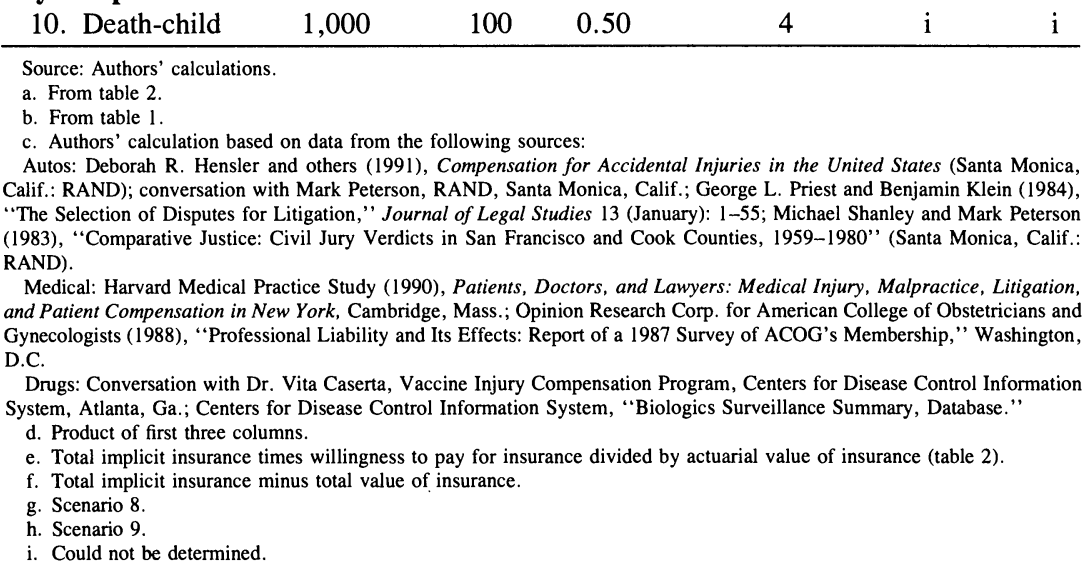


will come into play, whether or not product manufacturers are ultimately held liable. This applies particularly to the case of automobile accidents, where we have assumed that when a serious or fatal injury occurs, there is a 0.5 probability that either a manufacturer will be liable or an insurance firm will cover the pain and suffering liability of a driver or passenger. It should be understood that the probabilities used here are for demonstration purposes, to illustrate the potential effects of liability for pain and suffering, rather than to provide a careful estimate of actual liability under existing circumstances.

Total implicit insurance is the value of prevention (that is, level of damages) multiplied by the annual number of events (that is, injuries) and the probability of liability. Total value of insurance is implicit insurance times the ratio of willingness to pay for insurance to the actuarial value of insurance in the corresponding line in table 2 . For scenario 1 , total value of insurance is $\$ 16,834,000,000$ times $\$ 316$ / $\$ 440$ (from table 2), or $\$ 12,090,000,000$. The annual burden $(\$ 4,744,000,000)$ is the difference between total insurance and the value of that insurance. In scenarios with implicit probabilities, we estimated the value of prevention, as explained earlier. In these scenarios, we have provided calculations with values of prevention both lower and higher than the ones we estimated. This indicates how sensitive our burden estimates are to the values of prevention.

Table 3 (in which the middle line for each scenario is our best estimate) shows that the annual deadweight loss from overinsurance in automobile-related pain and suffering liability judgments potentially exceeds $\$ 1$ billion for each injury type, leading to a total annual loss from all injuries considered here of roughly $\$ 7$ billion (1992 dollars). Because we considered only about half of automobile deaths and a restricted range of injuries, the full burden of overinsurance in automobiles to consumers is likely to be some multiple of $\$ 7$ billion. This cost alone should be sufficient to motivate concern about the wisdom of using hedonic damages as a guide to setting pain and suffering awards.

In the medical scenarios, the gap between willingness to pay for prevention and the willingness to pay for insurance is wide, but the total burden is small because the probability of liability is small. The burden could actually be substantial, however, because (as we noted 
in discussing the estimation results for scenario 4) it is likely that the true willingness to pay to prevent a permanent disability from medical procedures is far greater than the estimated value of prevention of $\$ 24,000$. A larger value of prevention would translate into a large implicit insurance policy and, presumably, a larger burden from overinsurance.

In the case of drugs, the estimated burden was inherently small. We focused on infrequent events. Also, in scenarios 7 and 8, which had explicit probabilities, respondents simply offered the actuarial value for insurance, which was inexpensive due to the small probabilities involved. ${ }^{22}$ This did not happen in scenarios 4 and 6 , which had larger explicit probabilities. The results for drugs with greater risks could therefore be quite different from those reported here. The number of events involving day camps is also small, and, as explained, no loss was estimated because the price coefficient was unreliable.

Thus, although our aggregate estimate of the annual consumer burden from overinsurance totals several billion dollars, it is likely to be severely underestimated. We examined only a limited range of products, services, and injuries, some of which seldom occur. In one important scenario, involving permanent disability from medical procedures, the survey was biased toward a very low willingness to pay for prevention, which translated into small expected liability payments. An additional source of downward bias lay in the way the survey assessed willingness to pay for insurance. In most scenarios, the choices involved relatively small insurance premiums, either because the payouts were not large ( $\$ 100,000$ or less) or because the probability of loss was small. We extrapolated from these results to estimate willingness to pay for large policies of $\$ 1$ million or more. But the premiums for such policies are large enough to encounter income effects, that is, a diminishing marginal willingness to pay for larger policies. Because we ignored this effect, many of our estimates of willingness to pay for insurance are likely to be overestimates. We would expect to find lower willingness to pay for insurance in a survey that presented consumers with the actuarial cost of large insurance policies.

22. As explained in footnote 20 , a $\$ 100,000$ policy cost only $\$ 10$ in scenario 7 and $\$ 5$ in scenario 8 . 


\section{Conclusions and Policy Considerations}

Our results suggest that overinsurance from strict liability for pain and suffering is more than a theoretical possibility. Consumers faced with reasonable sets of choices were usually willing to pay more for prevention than for insurance, particularly in situations involving severe injury or death, combined with a probability of injury that was more than marginal. These are precisely the situations in which increasing the scope of liability for pain and suffering (to consistently include wrongful death, for example) is likely to generate large aggregate tort payments. In these situations, awarding payments for pain and suffering (assuming the awards correspond roughly to the hedonic damages criterion) has the effect of forcing consumers to purchase large insurance policies whose values, our results indicate, are less, often far less, than their actuarial cost.

Moreover, the true burden from overinsurance substantially exceeds our estimates, inasmuch as we considered only a small range of products and injuries and may have overestimated the value of insurance for those situations we did investigate. It is also possible that actual damage payments for pain and suffering would routinely exceed the hedonic measure we assumed. In addition, the increase in liability associated with pain and suffering payments would tend to increase total transaction costs and other inefficiencies associated with the liability system. Finally, we ignored indirect costs from liability such as reductions in the availability of products, including products that reduce risk. ${ }^{23}$ These, too, could be substantial.

Our results do not appear to be an artifact of survey design. The methods are similar to those routinely used by profit-seeking firms to assess potential demand for products not yet on the market. The results were robust in the sense of providing reasonable estimates for a wide variety of aspects of consumer choice, including subjective probabilities and the value (or lack of value) of various product attributes.

23. See Calfee and Rubin (1992) on a theoretical treatment of how liability for pain and suffering can increase the risk faced by consumers as a result of increases in the prices of products that reduce but do not eliminate risk. To the extent that liability prevents the introduction of products, firms would be more aware than consumers of the consequences of liability. It is significant, therefore, that a 1988 survey of 500 chief executive officers of large firms ranked a cap on liability damages for pain and suffering as one of the three tort liability reforms they most desired. 
Important aspects of the welfare effects of liability for pain and suffering remain unaddressed. Of particular interest, as stressed throughout the paper, is the matter of precautionary incentives. If other precautionary incentives are inadequate, liability for pain and suffering could provide a benefit from increased precautions that would tend to offset the cost of overinsurance. But adequate precautionary incentives could arise from reputational effects as well as from other sources, including regulation and liability for pecuniary losses.

Our findings raise the issue of possible policy responses. The most obvious issue is whether to prohibit damages for pain and suffering or at least to limit them to some approximation of willingness to pay for insurance against pain and suffering. The net effects of such a change would depend on the level of precautionary incentives arising from sources other than the liability system. If precautionary incentives from such sources are at or above the optimal level, then eliminating pain and suffering payments would move precautionary incentives from a supra-optimal level to one closer to the optimal level, which would be an additional benefit from halting payments for pain and suffering. If precautionary incentives from nonliability sources are suboptimal, the net effect of eliminating pain and suffering payments would depend on the extent to which incentives would fall short of the optimal level. If nonliability incentives are sufficiently short of optimal, the cost to consumers from inadequate incentives could exceed the overinsurance savings from eliminating pain and suffering payments.

Regardless of the level of precautionary incentives, contracting may be a better way to deal with pain and suffering damage payments. Consumers could be free to enter contracts with insurance companies that explicitly include or exclude pain and suffering damages. ${ }^{24}$ Our study suggests substantial welfare gains from such an approach, which would allow consumers to trade off the burden of involuntary insurance against the risk of inadequate precautions by firms. Our findings provide little support for the commonly expressed objection that consumers are unable or unwilling to face the chances of suffering serious injury or death and therefore cannot make reasonable contracting decisions.

24. Rubin (1993) suggested this approach for insurance generally; Horowitz and O'Connell (1992), specifically for auto insurance. 


\section{Appendix A. Choice Scenarios for Panel Survey}

This appendix contains two items for each scenario (except scenario $1 \mathrm{a}$ and $1 \mathrm{~b}$ in exhibit 1 ): a reproduction of the page that described the scenario to respondents, and a listing of the packages that respondents were asked to rank order. Respondents were given separate cards for each package and were asked to sort (that is, randomize) the cards before first rating and then ranking the packages. They were also asked for their age and gender. Respondents were members of a large, ongoing mail panel and thus were accustomed to receiving diverse sets of tasks involving preferences and other measures of use to market researchers.

\section{Scenario 2a}

Suppose you need to buy a car. After 2 weeks of looking, you have decided which model to buy. You still have to decide on the following items:

Price: The price of the automobile varies depending on the items contained in the package.

Engine Size: A larger engine is offered. It gets you slightly worse fuel economy than the standard engine, but makes the car accelerate from " 0 ", to " 60 " miles an hour in 10 seconds instead of 13 seconds for the standard engine.

Safety Package: The safety package cuts in half the chances of a child having a fatal accident.

Air Conditioning: Air conditioning is an option.

Note: There is NO difference in quality other than differences in the items contained in the package. Remember, the model of car is the same for each package except for the items mentioned in the package.

\begin{tabular}{ccccc}
\hline Package & Price & Engine size & Safety package & Air conditioner \\
\hline 1 & $\$ 10,000$ & Small & No & No \\
2 & 10,200 & Small & Yes & No \\
3 & 10,500 & Small & Yes & No \\
4 & 11,000 & Small & No & Yes \\
5 & 11,800 & Small & Yes & Yes \\
6 & 11,000 & Large & No & No \\
7 & 11,400 & Large & Yes & No \\
8 & 12,000 & Large & Yes & No \\
9 & 12,000 & Large & No & Yes \\
10 & 12,050 & Large & Yes & Yes \\
11 & 12,500 & Large & Yes & Yes \\
12 & 13,000 & Large & Yes & Yes \\
13 & 13,500 & Large & Yes & Yes \\
\hline
\end{tabular}




\section{Scenario 2b}

Suppose you need to buy a car. After 2 weeks of looking, you have decided which model to buy. You still have to decide on the following items:

Price: The price of the automobile varies depending on the items contained in the package.

Engine Size: A large engine is offered. It gets slightly worse fuel economy than the standard engine, but the car accelerates from " 0 " to " 60 " miles an hour in 10 seconds instead of 13 seconds for the standard small engine.

Insurance Policy: The insurance policy would pay money to your family (or designated beneficiary) if a child has a fatal accident while in this car. This money would be in addition to what ever life insurance they already have.

Air Conditioning: Air conditioning is an option.

Note: There is NO difference in quality other than differences in the items contained in the package. Remember, the model of car is the same for each package except for the items mentioned in the package.

\begin{tabular}{|c|c|c|c|c|}
\hline Package & Price & Engine size & Insurance payout & Air conditioner \\
\hline 1 & $\$ 10,000$ & Small & 0 & No \\
\hline 2 & 10,100 & Small & 10,000 & No \\
\hline 3 & 10,300 & Small & 500,000 & No \\
\hline 4 & 11,000 & Small & 0 & Yes \\
\hline 5 & 11,500 & Small & 100,000 & Yes \\
\hline 6 & 10,000 & Large & 0 & No \\
\hline 7 & 10,100 & Large & 50,000 & No \\
\hline 8 & 11,000 & Large & 100,000 & No \\
\hline 9 & 12,000 & Large & 0 & Yes \\
\hline 10 & 12,075 & Large & 100,000 & Yes \\
\hline 11 & 12,200 & Large & 200,000 & Yes \\
\hline 12 & 12,500 & Large & 500,000 & Yes \\
\hline 13 & 13,500 & Large & $1,000,000$ & Yes \\
\hline
\end{tabular}




\section{Scenario 3a}

Suppose you need to buy a car. After 2 weeks of looking, you have decided which model to buy. You still have to decide on the following items:

Price: The price of the automobile varies depending on the items contained in the package.

Engine Size: A larger engine is offered. It gets you slightly worse fuel economy than the standard engine, but makes the car accelerate from " 0 ", to " 60 " miles an hour in 10 seconds instead of 13 seconds for the standard engine.

Safety Package: The safety package cuts in half the chances of a child having crippling injuries that make it impossible for the victim to walk.

Air Conditioning: Air conditioning is an option.

Note: There is NO difference in quality other than differences in the items contained in the package. Remember, the model of car is the same for each package except for the items mentioned in the package.

\begin{tabular}{ccccc}
\hline Package & Price & Engine size & Safety package & Air conditioner \\
\hline 1 & $\$ 10,000$ & Small & No & No \\
2 & 10,200 & Small & Yes & No \\
3 & 10,500 & Small & Yes & No \\
4 & 11,000 & Small & No & Yes \\
5 & 11,800 & Small & Yes & Yes \\
6 & 11,000 & Large & No & No \\
7 & 11,400 & Large & Yes & No \\
8 & 12,000 & Large & Yes & No \\
9 & 12,000 & Large & No & Yes \\
10 & 12,050 & Large & Yes & Yes \\
11 & 12,500 & Large & Yes & Yes \\
12 & 13,000 & Large & Yes & Yes \\
13 & 13,500 & Large & Yes & Yes \\
\hline
\end{tabular}




\section{Scenario 3b}

Suppose you need to buy a car. After 2 weeks of looking, you have decided which model to buy. You still have to decide on the following items:

Price: The price of the automobile varies depending on the items contained in the package.

Engine Size: A large engine is offered. It gets slightly worse fuel economy than the standard engine, but the car accelerates from " 0 " to " 60 " miles an hour in 10 seconds instead of 13 seconds for the standard small engine.

Insurance Policy: The insurance policy would pay money to your family (or designated beneficiary) if a child has a crippling accident and will never be able to walk. This money would be in addition to payments for medical expenses.

Air Conditioning: Air conditioning is an option.

Note: There is NO difference in quality other than differences in the items contained in the package. Remember, the model of car is the same for each package except for the items mentioned in the package.

\begin{tabular}{|c|c|c|c|c|}
\hline Package & Price & Engine size & Insurance payout & Air conditioner \\
\hline 1 & $\$ 10,000$ & Small & $\$$ & No \\
\hline 2 & 10,100 & Small & 10,000 & No \\
\hline 3 & 10,300 & Small & 500,000 & No \\
\hline 4 & 11,000 & Small & 0 & Yes \\
\hline 5 & 11,500 & Small & 100,000 & Yes \\
\hline 6 & 10,000 & Large & 0 & No \\
\hline 7 & 10,100 & Large & 50,000 & No \\
\hline 8 & 11,000 & Large & 100,000 & No \\
\hline 9 & 12,000 & Large & 0 & Yes \\
\hline 10 & 12,075 & Large & 100,000 & Yes \\
\hline 11 & 12,200 & Large & 200,000 & Yes \\
\hline 12 & 12,500 & Large & 500,000 & Yes \\
\hline 13 & 13,500 & Large & $1,000,000$ & Yes \\
\hline
\end{tabular}




\section{Scenario 4a}

Suppose you have suffered a head injury in an accident. The only way to recover is by undergoing a very complicated operation. The recovery period is normally about three months. During this time, you also have to take a drug that must be injected once a day. In about one case out of a hundred, the onsration causes severe side effects in the form of headaches and nausea. If iney occur, these side effects will last for the rest of your life and will keep you in bed most of the time. Your health insurance will pay for the standard type of operation, but you can pay extra for an operation that provides the following features:

Side Effects: Some versions of the operation do not have the adverse side effects, while others do have the 1-in-100 chance for severe side effects.

Number Of Shots: Some versions of the operation require no shots for the 90-day recovery period, while others require the once-a-day shots for the 90-day recovery period.

Price: The extra amount you have to pay for the operation.

Note: A higher price does not mean an operation is more superior. The operations are identical in every way except for the items indicated above.

\begin{tabular}{crlc}
\hline Package & Price & Side effects & $\begin{array}{c}\text { Number of } \\
\text { daily shots }\end{array}$ \\
\hline 1 & $\$ 0^{\mathrm{a}}$ & Rare but severe & 1 \\
2 & 100 & None & 1 \\
3 & 500 & None & 1 \\
4 & 1,000 & None & 1 \\
5 & 100 & Rare but severe & None \\
6 & 400 & None & None \\
7 & 800 & None & None \\
8 & 1,200 & None & None \\
\hline
\end{tabular}

a. Standard version of the operation. 


\section{Scenario 4b}

Suppose you have suffered a head injury in an accident. The only way to recover is by undergoing a very complicated operation. The recovery period is normally about three months. During this time, you also have to take a drug that must be injected once a day. In about one case out of a hundred, the operation causes severe side effects in the form of headaches and nausea. If they occur, these side effects will last for the rest of your life and will keep you in bed most of the time. Your health insurance will pay for the standard type of operation, but you can pay extra for an operation and insurance that provides the following features:

Number Of Shots: Some versions of the operation require no shots for the 90-day recovery period, while others require the once-a-day shots for the 90-day recovery period.

Insurance Policy: Some versions of the operation come with an insurance policy that will provide money to you if you suffer side effects from the operation. Health insurance will cover all medical costs and disability insurance will make up for any lost income. So the insurance payout that comes with some versions of the operation would be in addition to money needed for medical costs or lost income.

Price: The extra amount you have to pay for the operation.

Note: A higher price does not mean an operation is more superior. The operations are identical in every way except for the items indicated above.

\begin{tabular}{crrr}
\hline Package & Price & $\begin{array}{c}\text { Number of } \\
\text { daily shots }\end{array}$ & Insurance payout \\
\hline 1 & $\$ 0^{\mathrm{a}}$ & 1 & $\$$ \\
2 & 100 & 1 & 0 \\
3 & 500 & 1 & 10,000 \\
4 & 1,000 & 1 & $1,000,000$ \\
5 & 100 & None & 000 \\
6 & 400 & None & 100,000 \\
7 & 800 & None & 500,000 \\
8 & 1,200 & None & $1,000,000$ \\
\hline
\end{tabular}

a. Standard version of the operation. 


\section{Scenario 5a}

Suppose you have suffered a head injury in an accident. The only way to recover is by undergoing a very complicated operation. The recovery period is normally about three months. During this time, you also have to take a drug that must be injected once a day. In rare cases, the operation causes severe side effects in the form of headaches and nausea. If they occur, these side effects will keep you in bed most of the time. After the three-month recovery period, the side effects will disappear. Your health insurance will pay for the standard type of operation, but you can pay extra for an operation that provides the following features:

Side Effects: Some versions of the operation do not have the adverse side effects, while others do have the rare, but severe side effects.

Number Of Shots: Some versions of the operation require no shots for the 90-day recovery period, while others require the once-a-day shots for the 90-day recovery period.

Price: The extra amount you have to pay for the operation.

Note: A higher price does not mean an operation is more superior. The operations are identical in every way except for the items indicated above.

\begin{tabular}{crlc}
\hline Package & Price & Side effects & $\begin{array}{c}\text { Number of } \\
\text { daily shots }\end{array}$ \\
\hline 1 & $\$ 0^{\mathrm{a}}$ & Rare but severe & 1 \\
2 & 100 & None & 1 \\
3 & 500 & None & 1 \\
4 & 1,000 & None & 1 \\
5 & 100 & Rare but severe & None \\
6 & 400 & None & None \\
7 & 800 & None & None \\
8 & 1,200 & None & None \\
\hline
\end{tabular}

a. Standard version of the operation. 


\section{Scenario 5b}

Suppose you have suffered a head injury in an accident. The only way to recover is by undergoing a very complicated operation. The recovery period is normally about three months. During this time, you also have to take a drug that must be injected once a day. In rare cases, the operation causes severe side effects in the form of headaches and nausea. If they occur, these side effects will keep you in bed most of the time. After the three-month recovery period, the side effects will disappear. Your health insurance will pay for the standard type of operation, but you can pay extra for an operation and insurance that provides the following features:

Number Of Shots: Some versions of the operation require no shots for the 90-day recovery period, while others require the once-a-day shots for the 90-day recovery period.

Insurance Policy: Some versions of the operation come with an insurance policy that will provide money to you if you suffer side effects from the operation. Health insurance will cover all medical costs, and disability insurance will make up for any lost income. So the insurance payout that comes with some versions of the operation would be in addition to money needed for medical costs or lost income.

Price: The extra amount you have to pay for the operation.

Note: A higher price does not mean an operation is more superior. The operations are identical in every way except for the items indicated above.

\begin{tabular}{crrr}
\hline Package & Price & $\begin{array}{c}\text { Number of } \\
\text { daily shots }\end{array}$ & Insurance payout \\
\hline 1 & $\$ 0^{\mathrm{a}}$ & 1 & $\$$ \\
2 & 100 & 1 & 0 \\
3 & 500 & 1 & 10,000 \\
4 & 1,000 & 1 & 100,000 \\
5 & 100 & None & $1,000,000$ \\
6 & 400 & None & 0 \\
7 & 800 & None & 100,000 \\
8 & 1,200 & None & 500,000 \\
\hline
\end{tabular}

a. Standard version of the operation. 


\section{Scenario 6a}

Suppose your family is expecting a child, and it is nearly time for labor to begin and you must have an anesthetic for pain. Your obstetrician explains that with any anesthetic there is a risk that the child will be born with a temporary handicap (often a heart problem). If the child is born with the handicap, the child will have to go through several operations and will be quite unhappy during his first year. After that, he should be completely normal. Your health insurance will pay for the standard type of anesthetic, but you can pay extra for an anesthetic that provides the following features:

Pain: Some versions involve substantially less pain than normal.

Length Of Labor: Some versions make labor 6 hours less than normal while other versions have no effect on the length of labor.

Risk Of Handicap: With the standard anesthetic, the chances of the temporary handicap is about 1 in 1,000. With an approved anesthetic, the chance is only about 1 in 2,000 .

Price: The extra amount you have to pay for the anesthetic, after the insurance pays the ordinary cost.

Note: A higher price does not mean an anesthetic is superior. The anesthetics are identical in every way except for the items indicated above.

\begin{tabular}{|c|c|c|c|c|}
\hline Package & Price & Pain & $\begin{array}{l}\text { Length } \\
\text { of labor }\end{array}$ & $\begin{array}{c}\text { Risk of } \\
\text { handicap }^{a}\end{array}$ \\
\hline 1 & $\$ 0^{b}$ & Usual & Usual & Usual \\
\hline 2 & 50 & Usual & Usual & Less \\
\hline 3 & 100 & Usual & Usual & Less \\
\hline 4 & 150 & Usual & $\begin{array}{l}\text { Six hours less } \\
\text { than usual }\end{array}$ & Usual \\
\hline 5 & 250 & Usual & $\begin{array}{l}\text { Six hours less } \\
\text { than usual }\end{array}$ & Less \\
\hline 6 & 350 & Usual & $\begin{array}{l}\text { Six hours less } \\
\text { than usual }\end{array}$ & Less \\
\hline 7 & 200 & Less than usual & Usual & Usual \\
\hline 8 & 275 & Less than usual & Usual & Less \\
\hline 9 & 350 & Less than usual & Usual & Less \\
\hline 10 & 225 & Less than usual & $\begin{array}{l}\text { Six hours less } \\
\text { than usual }\end{array}$ & Usual \\
\hline 11 & 250 & Less than usual & $\begin{array}{l}\text { Six hours less } \\
\text { than usual }\end{array}$ & Less \\
\hline 12 & 350 & Less than usual & $\begin{array}{l}\text { Six hours less } \\
\text { than usual }\end{array}$ & Less \\
\hline 13 & 500 & Less than usual & $\begin{array}{l}\text { Six hours less } \\
\text { than usual }\end{array}$ & Less \\
\hline
\end{tabular}

a. Usual risk of handicap is 1 in 1,000 ; less risk of handicap is 1 in 2,000 .

b. Using standard anesthetic. 


\section{Scenario $6 b$}

Suppose your family is expecting a child, and it is nearly time for labor to begin and you must have an anesthetic for pain. Your obstetrician explains that with any anesthetic there is a risk that the child will be born with a temporary handicap (often a heart problem). If the child is born with the handicap, the child will have to go through several operations and will be quite unhappy during his first year. After that, he should be completely normal. The chances of this kind of handicap is about 1 in 1,000. Your health insurance will pay for the standard type of anesthetic, but you can pay extra for an anesthetic that provides the following features:

Pain: Some versions involve substantially less pain than normal.

Length Of Labor: Some versions make labor 6 hours less than normal while other versions have no effect on the length of labor.

Insurance Policy With Payout: It is possible to get a special insurance policy that would pay money to your family if your child is born with the temporary handicap.

Price: The extra amount you have to pay for the anesthetic, after the insurance pays the ordinary cost.

Note: A higher price does not mean an anesthetic is superior. The anesthetics are identical in every way except for the items indicated above.

\begin{tabular}{|c|c|c|c|c|}
\hline Package & Price & Pain & $\begin{array}{l}\text { Length } \\
\text { of labor }\end{array}$ & $\begin{array}{c}\text { Insurance } \\
\text { payout }\end{array}$ \\
\hline 1 & $\$ 0^{\mathrm{a}}$ & Usual & Usual & $\$$ \\
\hline 2 & 25 & Usual & Usual & 50,000 \\
\hline 3 & 100 & Usual & Usual & 100,000 \\
\hline 4 & 200 & Usual & Usual & 200,000 \\
\hline 5 & 300 & Usual & $\begin{array}{l}\text { Six hours less } \\
\text { than usual }\end{array}$ & 0 \\
\hline 6 & 325 & Usual & $\begin{array}{l}\text { Six hours less } \\
\text { than usual }\end{array}$ & 10,000 \\
\hline 7 & 350 & Usual & $\begin{array}{l}\text { Six hours less } \\
\text { than usual }\end{array}$ & 100,000 \\
\hline 8 & 150 & Less than usual & Usual & 0 \\
\hline 9 & 250 & Less than usual & Usual & 50,000 \\
\hline 10 & 300 & Less than usual & $\begin{array}{c}\text { Six hours less } \\
\text { than usual }\end{array}$ & 0 \\
\hline 11 & 310 & Less than usual & $\begin{array}{l}\text { Six hours less } \\
\text { than usual }\end{array}$ & 20,000 \\
\hline 12 & 350 & Less than usual & $\begin{array}{l}\text { Six hours less } \\
\text { than usual }\end{array}$ & 50,000 \\
\hline 13 & 450 & Less than usual & $\begin{array}{c}\text { Six hours less } \\
\text { than usual }\end{array}$ & 100,000 \\
\hline
\end{tabular}

a. Using standard anesthetic. 


\section{Scenario 7a}

Suppose a new and dangerous flu epidemic is threatening the country. It is estimated that if nothing is done, about one person in every 10,000 will catch the flu and die (others will catch the flu and quickly recover). There is a vaccine that prevents you from getting the flu. The vaccine can have bad side effects which can be fatal. The chances of dying after taking the vaccine, however, are only about one-half as great-in other words, only about 1 in 20,000 . Your health insurance will pay for the standard vaccination, but you can pay extra for a vaccination that provides the following features:

Pain: Some versions of the vaccine are less painful to receive than others.

Number Of Shots: Some versions require three shots, whereas others require only one shot.

Price: The amount you have to pay for the vaccination.

Note: A higher price does not mean a vaccine is more superior. The vaccines are identical in every way except for the items indicated above.

\begin{tabular}{cclc}
\hline Package & Price & \multicolumn{1}{c}{ Pain } & $\begin{array}{c}\text { Number } \\
\text { of shots }\end{array}$ \\
\hline 1 & $\$ 0$ & None & None $^{\mathrm{a}}$ \\
2 & 10 & More painful & 3 \\
3 & 40 & More painful & 3 \\
4 & 30 & Less painful & 3 \\
5 & 50 & Less painful & 3 \\
6 & 30 & More painful & 1 \\
7 & 50 & More painful & 1 \\
8 & 40 & Less painful & 1 \\
9 & 50 & Less painful & 1 \\
10 & 80 & Less painful & 1 \\
\hline
\end{tabular}

a. No vaccine at all. 


\section{Scenario 7b}

Suppose a new and dangerous flu epidemic is threatening the country. It is estimated that if nothing is done, about one person in every 10,000 will catch the flu and die (others will catch the flu and quickly recover). There is a vaccine that prevents you from getting the flu. The vaccine can have bad side effects which can be fatal. The chances of dying after taking the vaccine, however, are only about one-half as great-in other words, only about 1 in 20,000. There are different vaccines to choose.

A higher price does not mean a vaccine is more superior. The vaccines are identical in every way except for the following items:

Price: The price of the vaccine varies depending on the items described below. The price includes both the vaccine and the insurance.

Pain: Some versions of the vaccine are less painful to receive than others.

Number Of Shots: Some versions require three shots, whereas others require only one shot.

Insurance Policy: Some versions of the vaccine come with an insurance policy that will provide money to your family if the vaccine is fatal. This money would be in addition to whatever money is needed to pay medical costs which you can assume are covered by health insurance. Your health insurance does not pay for the vaccine, however, and does not provide the insurance payout if there is a disability.

\begin{tabular}{ccccr}
\hline Package & Price & Pain & $\begin{array}{c}\text { Number } \\
\text { of shots }\end{array}$ & $\begin{array}{c}\text { Insurance } \\
\text { payout }\end{array}$ \\
\hline 1 & $\$ 10$ & More painful & 3 & $\$$ \\
2 & 15 & More painful & 3 & 0 \\
3 & 20 & More painful & 1 & 100,000 \\
4 & 30 & More painful & 1 & 0 \\
5 & 35 & More painful & 1 & 200,000 \\
6 & 50 & More painful & 1 & 400,000 \\
7 & 60 & More painful & 1 & 500,000 \\
8 & 50 & Less painful & 3 & $1,000,000$ \\
9 & 55 & Less painful & 3 & 0 \\
10 & 60 & Less painful & 3 & 100,000 \\
11 & 75 & Less painful & 3 & 300,000 \\
12 & 60 & Less painful & 1 & 500,000 \\
13 & 80 & Less painful & 1 & 0 \\
\hline
\end{tabular}




\section{Scenario 8a}

Suppose a new and dangerous virus has threatened the health of children. The virus causes a painful illness that often causes death. Your doctor wishes to give your child a vaccination to prevent this disease. The vaccine may have a side effect of causing brain damage. The chance that the vaccine will cause brain damage is about 1 in 10,000. This is much less than the chance of getting the dangerous illness if the child is not vaccinated. If there is brain damage, however, the child will be permanently disabled. There are different vaccines to choose.

The vaccines differ on the following items:

Price: The price of the vaccine varies depending on the items described below. Some versions of the vaccine cost more but they eliminate the chance of brain damage. The price includes both the vaccine and the extra features, if any.

Pain: Some versions of the vaccine are less painful to receive than others.

Number Of Shots: Some versions require three shots, whereas others require only one shot.

Risk Of Brain Damage: Some versions have a 1 in 10,000 risk of brain damage while others offer no risk at all.

\begin{tabular}{crlcc}
\hline Package & Price & Pain & $\begin{array}{c}\text { Number } \\
\text { of shots }\end{array}$ & $\begin{array}{c}\text { Risk of } \\
\text { brain damage }\end{array}$ \\
\hline 1 & $\$ 10$ & More painful & 3 & 1 in 10,000 \\
2 & 25 & More painful & 3 & None \\
3 & 20 & More painful & 1 & 1 in 10,000 \\
4 & 50 & More painful & 1 & None \\
5 & 100 & More painful & 1 & None \\
6 & 40 & Less painful & 3 & 1 in 10,000 \\
7 & 90 & Less painful & 3 & None \\
8 & 140 & Less painful & 3 & None \\
9 & 60 & Less painful & 1 & 1 in 10,000 \\
10 & 120 & Less painful & 1 & None \\
\hline
\end{tabular}




\section{Scenario 8b}

Suppose a new and dangerous virus has threatened the health of children. The virus causes a painful illness that often causes death. Your doctor wishes to give your child a vaccination to prevent this disease. The vaccine may have a side effect of causing brain damage. The chance that the vaccine will cause brain damage is about 1 in 10,000 . This is much less than the chance of getting the dangerous illness if the child is not vaccinated. If there is brain damage, however, the child will be permanently disabled. There are different vaccines to choose.

A higher price does not mean a vaccine is more superior. The vaccines are identical in every way except for the following items:

Price: The price of the vaccine varies depending on the items described below. The price includes both the vaccine and the extra features, if any.

Pain: Some versions of the vaccine are less painful to receive than others.

Number Of Shots: Some versions require three shots, whereas others require only one shot.

Cash Payout: Some versions of the vaccine provide a cash payout to your family if the vaccine causes brain damage. This money would be in addition to whatever money is needed to pay medical costs.

\begin{tabular}{crlcr}
\hline Package & Price & Pain & $\begin{array}{c}\text { Number } \\
\text { of shots }\end{array}$ & $\begin{array}{c}\text { Insurance } \\
\text { payout }\end{array}$ \\
\hline 1 & $\$ 10$ & More painful & 3 & $\$$ \\
2 & 20 & More painful & 3 & 0 \\
3 & 20 & More painful & 1 & 100,000 \\
4 & 30 & More painful & 1 & 0 \\
5 & 35 & More painful & 1 & 100,000 \\
6 & 60 & More painful & 1 & 200,000 \\
7 & 120 & More painful & 1 & 300,000 \\
8 & 50 & Less painful & 3 & $1,000,000$ \\
9 & 70 & Less painful & 3 & 0 \\
10 & 80 & Less painful & 3 & 100,000 \\
11 & 90 & Less painful & 3 & 300,000 \\
12 & 60 & Less painful & 1 & 500,000 \\
13 & 100 & Less painful & 1 & 0 \\
\hline
\end{tabular}




\section{Scenario 9a}

Suppose a new and dangerous virus has threatened the health of children. The virus causes a painful illness that often causes death. Your doctor wishes to give your child a vaccination to prevent this disease. The vaccine may have a side effect of causing brain damage. The chance that the vaccine will cause brain damage is much less than the chance of getting the dangerous illness if the child is not vaccinated. If there is brain damage, however, the child will be permanently disabled. There are different vaccines to choose.

The vaccines differ on the following items:

Price: The price of the vaccine varies depending on the items described below. Some versions of the vaccine cost more but they eliminate the chance of brain damage. The price includes both the vaccine and the extra features, if any.

Pain: Some versions of the vaccine are less painful to receive than others.

Number Of Shots: Some versions require three shots, whereas others require only one shot.

Risk Of Brain Damage: Some versions have a small risk of brain damage while others offer no risk at all.

\begin{tabular}{crlcc}
\hline Package & Price & Pain & $\begin{array}{c}\text { Number } \\
\text { of shots }\end{array}$ & $\begin{array}{c}\text { Risk of } \\
\text { brain damage }\end{array}$ \\
\hline 1 & $\$ 10$ & More painful & 3 & Small \\
2 & 25 & More painful & 3 & None \\
3 & 20 & More painful & 1 & Small \\
4 & 25 & More painful & 1 & None \\
5 & 30 & More painful & 1 & None \\
6 & 50 & More painful & 1 & None \\
7 & 60 & More painful & 1 & None \\
8 & 40 & Less painful & 3 & Small \\
9 & 50 & Less painful & 3 & None \\
10 & 70 & Less painful & 3 & None \\
11 & 100 & Less painful & 3 & Small \\
12 & 60 & Less painful & 1 & None \\
13 & 120 & Less painful & 1 & \\
\hline
\end{tabular}




\section{Scenario 9b}

Suppose a new and dangerous virus has threatened the health of children. The virus causes a painful illness that often causes death. Your doctor wishes to give your child a vaccination to prevent this disease. The vaccine may have a side effect of causing brain damage. The chance that the vaccine will cause brain damage is much less than the chance of getting the dangerous illness if the child is not vaccinated. If there is brain damage, however, the child will be permanently disabled. There are different vaccines to choose.

A higher price does not mean a vaccine is more superior. The vaccines are identical in every way except for the following items:

Price: The price of the vaccine varies depending on the items described below. The price includes both the vaccine and the extra features, if any.

Pain: Some versions of the vaccine are less painful to receive than others.

Number Of Shots: Some versions require three shots, whereas others require only one shot.

Cash Payout: Some versions of the vaccine provide a cash payout to your family if the vaccine causes brain damage. This money would be in addition to whatever money is needed to pay medical costs.

\begin{tabular}{crlcr}
\hline Package & Price & Pain & $\begin{array}{c}\text { Number } \\
\text { of shots }\end{array}$ & $\begin{array}{r}\text { Insurance } \\
\text { payout }\end{array}$ \\
\hline 1 & $\$ 10$ & More painful & 3 & $\$$ \\
2 & 20 & More painful & 3 & 0 \\
3 & 20 & More painful & 1 & $1,000,000$ \\
4 & 25 & More painful & 1 & 0 \\
5 & 30 & More painful & 1 & 100,000 \\
6 & 35 & More painful & 1 & 500,000 \\
7 & 50 & More painful & 1 & $1,000,000$ \\
8 & 50 & Less painful & 3 & $1,000,000$ \\
9 & 70 & Less painful & 3 & 0 \\
10 & 80 & Less painful & 3 & 100,000 \\
11 & 100 & Less painful & 3 & 500,000 \\
12 & 60 & Less painful & 1 & $1,000,000$ \\
13 & 70 & Less painful & 1 & $1,000,000$ \\
\hline
\end{tabular}




\section{Scenario 10a}

Suppose you have a boy or girl about 8 years old and you are going to send your child to a day camp for the summer. There are several camps in your area. Each camp lasts 4 weeks and sessions run Monday through Friday from 9:30 a.m. to 3:00 p.m. Transportation to and from camp is provided.

A higher price for a camp does not mean a camp is more superior. The camps are identical in every way except in the following items:

Price: The price for attending the camp varies depending on the items contained in the package. A higher price does not mean the quality of the camp is any better.

Safety Plan: Also, some of the camps are participating in a new safety plan worked out with help from the federal government. This plan eliminates many of the dangers of summer camp. If the camp uses the plan, the chances of a camper suffering a fatal accident are only half of what they would be if the plan was not used. The plan does tend to make camps more expensive.

Children Per Counselor: Some camps take in more children per counselor than others do. The camps with fewer children per counselor give more personal attention.

\begin{tabular}{cccc}
\hline Package & Price & $\begin{array}{c}\text { Safety } \\
\text { plan }\end{array}$ & $\begin{array}{c}\text { Children per } \\
\text { counselor }\end{array}$ \\
\hline 1 & $\$ 400$ & No & 16 \\
2 & 425 & Yes & 16 \\
3 & 500 & Yes & 16 \\
4 & 600 & Yes & 16 \\
5 & 500 & No & 8 \\
6 & 540 & Yes & 8 \\
7 & 600 & Yes & 8 \\
8 & 650 & Yes & 8 \\
\hline
\end{tabular}




\section{Scenario 10b}

Suppose you have a boy or girl about 8 years old and you are going to send your child to a day camp for the summer. There are several camps in your area. Each camp lasts 4 weeks and sessions run Monday through Friday from 9:30 a.m. to 3:00 p.m. Transportation to and from camp is provided.

A higher price for a camp does not mean a camp is more superior. The camps are identical in every way except in the following items:

Price: The price for attending the camp varies depending on the items contained in the package. A higher price does not mean the quality of the camp is any better.

Insurance Policy: Also, some camps offer an insurance policy for your child and some do not. If there is a policy, it provides money to you and your family if your child suffers a fatal accident while at camp. Different camps offer different policies with different payouts.

Children Per Counselor: Some camps take in more children per counselor than others do. The camps with fewer children per counselor give more personal attention.

\begin{tabular}{|c|c|c|c|}
\hline Package & Price & $\begin{array}{c}\text { Insurance } \\
\text { payout }\end{array}$ & $\begin{array}{c}\text { Children per } \\
\text { counselor }\end{array}$ \\
\hline 1 & $\$ 400$ & $\$$ & 16 \\
\hline 2 & 425 & 100,000 & 16 \\
\hline 3 & 500 & 300,000 & 16 \\
\hline 4 & 600 & 500,000 & 16 \\
\hline 5 & 700 & $1,000,000$ & 16 \\
\hline 6 & 500 & 0 & 8 \\
\hline 7 & 540 & 100,000 & 8 \\
\hline 8 & 600 & 400,000 & 8 \\
\hline 9 & 580 & 200,000 & 8 \\
\hline 10 & 650 & $1,000,000$ & 8 \\
\hline
\end{tabular}




\section{Appendix B}

Table B-1. Estimation Results for Other Parameters

\begin{tabular}{|c|c|c|c|}
\hline Scenario & $\begin{array}{c}\text { Coefficient }^{a} \\
(t \text {-stat. })\end{array}$ & Scenario & $\begin{array}{c}\text { Coefficient }^{a} \\
(t \text {-stat. })\end{array}$ \\
\hline Auto-Death-Self & & Drug-Death-Self & \\
\hline $1 \mathrm{a}(\mathrm{n}=546)^{\mathrm{b}}$ & & $7 \mathrm{a}(\mathrm{n}=490)$ & \\
\hline Larger engine & $-0.020(2.0)$ & Less pain & $1.07(9.4)$ \\
\hline Air conditioner & $-1.78(19)$ & Fewer shots & $1.14(10)$ \\
\hline $1 \mathrm{~b}(\mathrm{n}=481)$ & & $7 \mathrm{~b}(\mathrm{n}=741)$ & \\
\hline Larger engine & $0.066(0.7)$ & Less pain & $-4.61(15)$ \\
\hline Air conditioner & $-1.06(10)$ & Fewer shots & $-1.12(8.8)$ \\
\hline Auto-Death-Child & & Drug-Perm.-Child & \\
\hline $2 \mathrm{a}(\mathrm{n}=611)$ & & $8 \mathrm{a}(\mathrm{n}=550)$ & \\
\hline Larger engine & $0.071(0.8)$ & Less pain & $0.522(3.8)$ \\
\hline Air conditioner & $-1.40(15)$ & Fewer shots & $0.481(5.6)$ \\
\hline $2 b(n=546)$ & & $8 \mathrm{~b}(\mathrm{n}=689)$ & \\
\hline Larger engine & $0.136(1.4)$ & Less pain & $-3.25(14)$ \\
\hline Air conditioner & $-1.50(15)$ & Fewer shots & $-0.605(5.6)$ \\
\hline Auto-Perm.-Child & & $9 \mathrm{a}(\mathrm{n}=650)$ & \\
\hline $3 \mathrm{a}(\mathrm{n}=559)$ & & Less pain & $0.683(4.6)$ \\
\hline Larger engine & $-0.104(1.1)$ & Fewer shots & $0.678(4)$ \\
\hline Air conditioner & $-1.30(14)$ & $9 \mathrm{~b}(\mathrm{n}=650)$ & \\
\hline $3 b(n=520):$ & & Less pain & $-1.75(10)$ \\
\hline Larger engine & $0.328(3.4)$ & Fewer shots & $0.327(4)$ \\
\hline Air conditioner & $-1.16(12)$ & Day Camp-Death-Child & \\
\hline Medical-Perm.-Self & & $10 \mathrm{a}(\mathrm{n}=512)$ & \\
\hline $4 a(n=368)$ & & Fewer children per & \\
\hline Fewer shots & $0.114(1.1)$ & counselor & $0.0896(9.1$ \\
\hline $4 b(n=360):$ & & $10 b(n=480):$ & \\
\hline Fewer shots & $0.115(1.0)$ & Fewer children per & \\
\hline Medical-Temp.-Self & & counselor & $0.0930(11)$ \\
\hline $5 a(n=456)$ & & & \\
\hline No shots & $-0.036(0.4)$ & & \\
\hline $5 \mathrm{~b}(\mathrm{n}=352)$ & & & \\
\hline No shots & $-0.071(0.6)$ & & \\
\hline \multirow{2}{*}{\multicolumn{4}{|c|}{ Medical-Temp.-Child }} \\
\hline & & & \\
\hline Less pain & $-0.021(0.3)$ & & \\
\hline Shorter labor & $-0.081(0.8)$ & & \\
\hline \multicolumn{4}{|l|}{$6 \mathrm{~b}(\mathrm{n}=520)$} \\
\hline Less pain & $-0.183(1.41)$ & & \\
\hline Shorter labor & $-0.699(2.9)$ & & \\
\hline
\end{tabular}

Source: Authors' calculations.

a. Positive coefficients indicate undesirable attributes, and vice versa.

b. $\mathrm{n}=$ number of respondents times number of packages per respondent. 


\section{Comments and Discussion}

Comment by W. Kip Viscusi: The Calfee and Winston paper focuses on the role of pain and suffering compensation in tort liability contexts. In a novel approach the authors utilize survey information to ascertain the value that individuals would place on insurance for pain and suffering losses.

Compensation for pain and suffering and related nonpecuniary losses is actually much broader than their paper indicates. In most contexts pain and suffering is the shorthand used to summarize all components of nonpecuniary compensation received by accident victims. The pain and suffering associated with an accident and its subsequent effects on the injured person's health clearly enter into the calculation of pain and suffering damages, but they represent only one nonpecuniary loss component. In the case of a fatality, there is compensation for loss of consortium and companionship. Mental anguish is also a prominent concern in many jurisdictions. Family members may be compensated for grief, and there also may be compensation in some states for loss of the enjoyment of life. For simplicity I will use the pain and suffering designation to include all nonpecuniary losses.

It is helpful to begin by considering the levels of pain and suffering compensation actually paid in tort liability contexts. In particular, do injured parties, on average, receive more than the value of their economic loss, which would indicate the presence of some compensation for pain and suffering and other nonpecuniary losses? The mean total value of payments for product liability cases settled out of court is greater than the value of losses if the size of the loss is below $\$ 100,000$, and the rate of replacement of the loss is less than 1.0 for loss amounts 
Table 1. Pain and Suffering Awards in 1977 Claims Sample from Insurance Services Office

\begin{tabular}{lc}
\hline Type of injury & $\begin{array}{c}\text { Fraction of } \\
\text { payment for } \\
\text { pain, } \\
\text { suffering }\end{array}$ \\
\hline Amputation & 0.51 \\
Asphyxiation & 0.47 \\
Brain damage & 0.38 \\
Bruise & 0.49 \\
Burn & 0.57 \\
Cancer & 0.54 \\
Concussion & 0.50 \\
Dermatitis & 0.41 \\
Dislocation & 0.42 \\
Disease-other & 0.48 \\
Electrical shock & 0.41 \\
Fracture & 0.30 \\
Laceration & 0.51 \\
Para/quadriplegia & 0.26 \\
Poisoning & 0.46 \\
Respiratory & 0.41 \\
Sprain/strain & 0.50 \\
Other & 0.35 \\
\hline
\end{tabular}

Source: Viscusi (1991, p. 103).

greater than $\$ 100,000 .{ }^{1}$ Similar patterns are borne out for cases that go to trial as well as for other types of personal injuries. In particular, there tends to be an overcompensation of small loss claims and undercompensation of larger loss claims.

The fraction of compensation for pain and suffering damages varies by injury type. Table 1 reports the fraction of compensation devoted to pain and suffering for a series of categories of injury in product liability cases. The fraction of compensation for pain and suffering ranges from 0.26 for para/quadriplegia to 0.57 for burn victims. Overall, the performance of pain and suffering compensation varies quite systematically with the character of the injury. In particular, there is a strong positive income elasticity of the value of pain and suffering amounts with the dollar value of the economic loss. The amount of pain and suffering compensation, however, is not simply a proportional 
markup of the economic loss. Controlling for the economic loss, pain and suffering compensation varies with the type of injury in a reasonable manner. For example, severe injuries, such as those associated with burns, tend to be more highly compensated than are temporary injuries, such as poisonings.

From an economic standpoint, there are two rationales for pain and suffering compensation. First, pain and suffering compensation can help create efficient financial incentives for accident avoidance. Elsewhere, I advocate the use of pain and suffering compensation in situations where providing safety incentives is important. ${ }^{2}$ In the case of fatalities, this would lead to use of the value of life numbers currently used to assess the stringency of government risk regulations. Since the deterrence aspects of pain and suffering are not the focus of the Calfee and Winston paper, I will not dwell on them here. Nevertheless, when making any policy judgments about the desirability of pain and suffering compensation, one must be cognizant of the deterrence of pain and suffering awards and not simply the insurance function that is the focus of their paper.

The second economic role of pain and suffering compensation is to provide insurance for losses that have been experienced. The optimal insurance amount for pain and suffering is the focus of the Calfee and Winston analysis. If individuals could purchase insurance for pain and suffering, which they cannot now do, would they choose to provide such compensation for themselves after having experienced an injury? Market evidence regarding the failure of insurance firms to offer pain and suffering insurance may not be conclusive since the presence of pain and suffering and its severity may be difficult for the insurer to monitor, thus creating problems of moral hazard. Using surveys such as that developed by Calfee and Winston, one could ascertain whether there is an underlying economic rationale for insuring against pain and suffering losses.

Although deterrence and insurance are clearly the most salient concerns of economists, pain and suffering compensation in practice entails much more. Plaintiffs must utilize some of their award to pay for their legal fees. The usual contingency fee arrangements require payment of one-third of the award to the plaintiff's attorney. Compensation for pain

2. Viscusi (1991, especially chap. 5). 
and suffering damages gives plaintiffs additional financial leeway to enable them to pay their attorneys and at the same time meet their economic needs. Juries may provide pain and suffering compensation in part as a mechanism for transferring funds to plaintiffs for this purpose. If we were to limit pain and suffering compensation in some manner, then other components of the award might adjust so that juries could continue to provide for plaintiffs' legal expenses. If awards were not increased and if there were no pain and suffering compensation, individuals would not be fully compensated for their economic losses because such compensation would not take into account the deduction that must be made for legal expenses. ${ }^{3}$

One impetus for scheduling or capping pain and suffering compensation is that as a practical matter juries may not have precise guidance for setting the level of pain and suffering compensation. Although some have suggested that juries are completely random and capricious in their awards of pain and suffering, these criticisms are not consistent with the empirical evidence on pain and suffering compensation, which varies quite systematically with injury type. ${ }^{4}$ Nevertheless, there is no well-defined formula that juries can implement to establish pain and suffering levels. Research such as that by Calfee and Winston can further our understanding of the optimal levels of pain and suffering compensation insurance and can assist in informing jurors of how such compensation levels should be set. There should be substantial changes, however, in the structure of their survey, which I will delineate below.

\section{Theoretical Background}

The theoretical issues in the context of pain and suffering compensation are well defined. In situations in which losses to the accident victim are purely financial, the individual's utility function is not affected by the accident. Full insurance of losses will be optimal.

In contrast, if the utility function alters with an injury, the optimal

3. One recent proposal was to establish a separate component of compensation for legal fees. In particular, the American Law Institute (1991) has considered proposals that would establish a schedule for pain and suffering compensation and provide separate compensation to plaintiffs for their legal expenses.

4. See Viscusi (1991, chap. 5) for supporting discussion. 
level of insurance will not provide for full loss replacement. If the marginal utility of income increases with an injury, more than full compensation will be optimal. If the marginal utility of income decreases with an injury, then less than full compensation will be optimal.

These judgments pertain only to situations in which the matter of concern is the optimal level of insurance. If deterrence is an issue, then there will be a rationale for providing a level of compensation that exceeds the optimal insurance amount in situations where the injury decreases the marginal utility income. This level of compensation will fall short of the implicit value of the injury from the standpoint of prevention because of the inherent trade-off that exists between the provision of incentives for injury avoidance and the provision of optimal insurance.

The effect of the accident on the marginal utility income is an empirical issue. Few would question that severe accidents such as fatalities decrease one's marginal utility income. An individual also could experience a decrease in marginal utility income after becoming a paraplegic or suffering severe brain damage. One cannot generalize, however, to all nonfatal injuries such as disabilities and conclude that the marginal utility of income has been diminished. One might hypothesize, for example, that expenditures on vans, computers, and handicap-accessible houses would be highly valued by many victims of injuries. These types of consumption items, however, are generally included as part of the rehabilitation package, and they need not be considered under the pain and suffering component of the award.

The linkage of pain and suffering at the time of injury to optimal insurance is unclear. At the time when the insurance will be paid, the pain and suffering related to the injury will have already been experienced. Compensation will be paid when the accident victim is healthy. In such a context, it is difficult to justify the award of pain and suffering based on the structure of individual utility functions after the victim's recovery. The primary rationale presumably should be that of deterrence. Society wishes to establish incentives for individuals not to inflict accidents that cause pain and suffering as well as economic loss.

One source of evidence on setting the optimal level of pain and suffering compensation is to determine how much insurance individuals desire in other contexts. Although social insurance purchases for programs such as workers' compensation do not represent voluntary con- 
sumer decisions, one can utilize the empirical evidence derived from these efforts to obtain some insight into the optimal level of pain and suffering compensation.

In the case of the workers' compensation program, the general formula for workers' compensation earning replacement provides for twothirds replacement of gross earnings of workers. The replacement formula, however, is more complicated than a simple earnings replacement rate. It includes a variety of floors, caps, and tax advantages. On balance, the effective rate of replacement of the earnings of typical injured workers exceeds the two-thirds amount.

Based on the rate of wage offset for workers' compensation benefits, one can determine whether the level of insurance being provided is optimal, less than optimal, or more than optimal. ${ }^{5}$ If workers accept a wage cut for additional benefits that exceeds the actuarial value of these benefits, then benefit levels are too low. In the case of the University of Michigan's Quality of Employment Survey, the actuarially fair reference point trade-off rate for an additional dollar of worker compensation benefits is -0.04 , whereas the actual wage offset value for workers is -0.12 . For the 1982 University of Michigan Panel Study of Income Dynamics, the actuarially fair reference point trade-off rate is -0.05 , whereas the actual trade-off is -0.08 . Finally, for the 1982 Viscusi-O'Connor chemical worker survey, the actuarially fair reference point trade-off value is -0.09 , and the observed trade-off rate is -0.15 .

These various studies do not enable us to identify the optimal value of workers' compensation benefits. It is clear, however, based on the excess of the observed trade-off rate above the actuarially fair tradeoff rate, that workers would prefer a higher level of benefits than the standard two-thirds wage replacement. These findings do not necessarily imply that workers' compensation benefits are not socially optimal, since moral hazard considerations enter as well. But from the standpoint of optimal insurance, the effect of job injuries on welfare is not so great as to make substantial reduction in the rate of wage replacement below full replacement desirable.

5. The empirical evidence addressed below, most of which is based on my joint research with Michael J. Moore, is discussed in detail in Viscusi (1992, chap. 5). 
Another approach that one can utilize to assess optimal pain and suffering compensation is to examine the structure of individual utility functions. Although utility functions cannot be estimated using observed market data, survey data regarding hypothetical market experiments can be utilized. Observations pertaining to the current wagerisk (or price-risk) combinations chosen by an individual can be used in conjunction with the wage increase (price change) that would be required to incur an increase in risk to establish two points on a constant expected utility locus. With this information, one can estimate the structure of individual utility functions and derive from this structure an estimate of the optimal replacement rate, which in turn provides information regarding the level of pain and suffering compensation.

Estimates using logarithmic utility functions indicate that for utility function given by $\ln y$ for workers injured on the job, the estimated utility function when healthy is $1.08 \ln y .{ }^{6}$ For lost workday injuries, the optimal replacement rate is 0.85 - greater than the current workers' compensation rate but less than the replacement rate that one would choose if there were full earnings replacement augmented by positive pain and suffering compensation.

Although there is no evidence supporting the desire to ensure pain and suffering compensation in the case of job injuries, for less severe product injuries the evidence is consistent with such compensation. ${ }^{7}$ For eight household injury types such as insecticide inhalation, insecticide skin poisoning, and toilet bowl cleaner gassings, estimated utility functions suggest that the structure of utility functions is not affected. Consumers treated these outcomes as being tantamount to monetary equivalents, where the magnitude of the loss ranged from $\$ 482$ to $\$ 2,482$ in terms of their equivalent monetary value. In situations in which injuries have an impact that is equivalent to a drop in income, as these minor injuries are estimated to have, it will be optimal to provide for full insurance of the income loss. Thus, pain and suffering compensation is potentially desirable from the standpoint of optimal insurance in the case of these minor injuries, whereas it is apparently not as desirable in the case of more severe outcomes.

6. These estimates reported in Viscusi and Evans (1990) are similar in character to those using other functional forms, such as a Taylor series expansion.

7. See Evans and Viscusi (1991). 


\section{Survey Issues}

The general approach taken by Calfee and Winston is similar to my work with Evans estimating utility functions. Calfee and Winston also rely on survey data. The main difference is that instead of inferring the optimal value of pain and suffering compensation from estimates of individual utility functions, they confront respondents directly with the pain and suffering insurance questions. The general idea of using survey data to obtain a firmer assessment of the optimal level of pain and suffering insurance is a good one, and the authors should be commended for introducing a new survey approach to this issue.

Calfee and Winston attempt to distance themselves from survey methodologies generally known as contingent valuation. Their approach, however, is very much a contingent valuation study. They use a survey method and a hypothetical market context to elicit individual preferences with regard to potential insurance options. Their approach does not require that individuals assess nonuse values or existence values for scarce animal species, as have some of the more hotly debated natural resource damage assessments. Consequently, their survey is likely to be more pertinent to decisions people actually make than are some contingent valuation studies.

A good feature of the Calfee and Winston survey is that it is not completely open-ended; they attempt to provide some structure-choice among different insurance options - for individuals to make meaningful decisions. Their survey is based on some products that have counterparts in reality and on choices that involve a familiar choice context as well as variants of products with which respondents should be familiar.

Their general survey approach is to ask respondents to rank order a variety of insurance packages. This approach has some antecedents in the contingent valuation literature. The most direct antecedent is the use of a series of paired comparisons in my research with Wesley Magat. We give consumers a sequence of risk-price pairs and iterate these choices until indifference is established. In addition, we have used conjoint analysis that involves a scoring of alternatives based on a quantitative metric. The rank-order approach also bears similarities to the use of a hypothetical referendum in contingent valuation studies.

The Calfee-Winston survey was a mail survey using a sample of experienced survey respondents. The one potential shortcoming of a 
mail survey, particularly with fairly difficult tasks such as the ones the authors gave to respondents, is that respondents may be less attentive than they would be in an in-person interview. ${ }^{8}$

The main finding of their study is that the optimal level of pain and suffering compensation is not great and may even be negative. This statement is from the standpoint of insurance, not deterrence. Although the authors emphasize that their survey is still in the "exploratory" phase, the overall character of the results that they find is believable. However, numerous specific questions are raised by their study that merit further exploration since this paper promises to be the first of similar efforts in the future.

\section{Survey Sophistication}

In my studies with Wesley Magat, we focused on choice contexts in which individuals were presented with two choices involving two product attributes (price and risk). ${ }^{9}$ Such fairly simple choice tasks involving familiar contexts, such as household insecticides, can be handled by most respondents. Nevertheless, a reasonable number of respondents failed basic rationality tests, such as not being able to identify situations of dominance. In some cases, this failure may stem from not being sufficiently attentive to the survey task. To foster more reliable elicitation of respondents' preferences, our surveys have incorporated an interactive loop. Individuals who fail the original dominance question are given an explanation of the nature of their mistake and are recycled through the dominance question. This question must be answered correctly before they can proceed with the remainder of the survey. In addition, we have explored a wide variety of consistency tests to determine the within-survey rationality of respondents.

Similar types of issues arise with respect to the Calfee and Winston survey. Even though their survey does not include a loop to educate respondents on consistent choices, it does include dominance relation-

8. Selectivity bias issues also arise with respect to the response rate for the survey as well as with respect to reliance on a sample that is based on a group of experienced survey takers who have volunteered to be regular survey participants in this and other surveys.

9. See, among other studies, Viscusi and Magat (1987); Viscusi, Magat, and Huber (1991); Magat and Viscusi (1992); and Magat, Viscusi, and Huber (1992). 
ships that they could explore. In the case of scenario $1 \mathrm{a}$, alternative 2 dominates 3,7 dominates 8,10 dominates 11,11 dominates 12 , and 12 dominates 13 . What percentage of individuals satisfied all of these different dominance relationships? Assessing these relationships will provide insight into the validity of the survey responses and the degree to which respondents were meaningfully engaged in the survey task.

Even if the simple dominance tests are met, the validity of the responses may be questionable because of the extreme complexity of the survey task. Are individuals truly capable of ranking the various alternatives in the survey time, which the authors estimate to be less than ten minutes? In the case of scenario $1 \mathrm{a}$, respondents are presented with thirteen insurance packages, each of which is characterized by four different attributes. This is a difficult task for professional economists, much less for the representative individuals who are purported to be the target audience. This survey far exceeds the intellectual demands placed on respondents in the typical contingent valuation study or consumer marketing survey. One wonders whether one would elicit the same answer if such a complex task were given to the respondent the next month.

Respondents may answer the survey questions without developing some formal or informal heuristics to cope with the complexity of the choice. If individuals develop their own heuristics, it would be interesting to explore what mechanisms they used to cope with the inordinately complex task. Since heuristics were apparently presented to them, one would want to know which specific heuristics the survey provided them, how these heuristics were used, and whether individuals adopted their own heuristics as well.

Most important, how do these heuristics affect the decision process? The psychology literature on choice under uncertainty suggests that the influence of such heuristics is typically not neutral. Given the complexity of the survey constructed by the authors, we may be measuring the results of decisionmaking with complex choices more than the specific trade-offs of interest. Rather than utilize such a complex formulation with intervening heuristics with uncertain implications, it would be preferable to utilize a more manageable set of choices that are more in line with the respondents' capabilities. 


\section{The Abruptness of the Choice}

Most households purchase several types of insurance. Thus, the hypothetical market is not completely foreign. It would have been useful, however, to assess the respondents' familiarity with the task since insurance purchases may have been handled by spouses. Moreover, none of the respondents would have familiarity with buying insurance for contexts for which insurance is not now offered, such as those involving pain and suffering. The typical insurance policy is linked more to the nature of the medical treatment than to the level of expenditure.

There is the danger that respondents undervalued pain and suffering insurance because the potential value of such insurance was never adequately explained. The survey, to be successful, must create a choice context for a product that does not now exist. One cannot assume, as the authors appear to have done, that respondents have already thought about why they might purchase this nonexistent product. It would have been useful to include a series of questions to set the context of the survey. The main challenge of any contingent valuation survey is to make respondents think through their hypothetical market decision. This is preferable to abruptly giving them a choice with which they may not yet be familiar.

To establish a meaningful survey context, the survey should have begun by asking respondents what the accident means to them. In particular, the survey instrument should have explored the insurance coverage the respondents currently have, the amount of income the respondents make, and the amount the respondents would like as compensation. The survey should have provided much more detailed information about the health outcomes of the respondent as well as about his likely needs after the adverse event. In the case of scenario $2 b, a$ child is killed, but we don't know how many children the respondent has (if any), whether there are any medical expenses, or why one would even want compensation in such a context. It is no wonder that respondents place little value on such insurance.

In our studies of health outcomes for diseases such as cancer and chronic bronchitis, we have incorporated extensive components of the survey-several times longer than the entire Calfee and Winston survey instrument-to establish what these health outcomes would mean to the individual's well-being. It is certainly not sufficient to tell people 
that their child will suffer "brain damage"' and leave it at that. Contingent valuation studies such as Calfee and Winston's deal with hypothetical contexts. To obtain results that mirror decisions made in actual market situations, one must provide sufficient detail for a meaningful decision to be made.

\section{Accuracy of the Risk Information}

At various junctures in the survey, the authors give the respondents risk information pertaining to the probabilities of different events. If the individuals take these probabilities at face value, then there is not a major source of error introduced into the analysis even if the probabilities are not correct. If, however, the probabilities do not accord with individual judgments, there is likely to be a substantial chance that the responses to the survey will be with respect to probabilities other than those stated in the survey instrument. In such a case, the authors' calculations pertaining to the attractiveness of insurance will not be legitimate. For example, many risk-averse consumers would pay less than the stated actuarial cost of insurance if the assessed probabilities by the insurer were much higher than those perceived by the individual purchaser. The authors should provide documentation of the accuracy of the various probabilities stated in this survey.

Such documentation is particularly important since some of the risks appear to be surprising. For example, the risk of heart problems from anesthesia in childbirth is stated as being 1 in 1,000 . If indeed the risk were this high, it probably would provide a fairly compelling case for natural childbirth. Similarly, the fatality risk of flu of 1 in 10,000 appears too great for most respondents. If this risk is true, then one would want to know the pertinence of this probability to the respondent's situation. The fatality victims of flu are predominantly the elderly, many of whom face a high mortality risk from a variety of cases. The probability that is pertinent to most of the survey respondents is certainly much lower than 1 in 10,000. Ideally, the risks should have been adjusted to reflect the differing health hazards for younger respondents. It also would have been useful to include in the questionnaire a section that would, in effect, debrief the respondents with respect to whether they believed the stated probability and its pertinence to their own health. 


\section{Probability Misperception}

Even if the probabilities stated in the survey are correct, individuals may not perceive them to be so. In situations in which there is individual control over the risk, individuals frequently underestimate the risks they face. The situations of automobile accidents and child safety risks are two of the best-documented instances where individuals believe that their own risks are much lower than those of the typical driver and the typical household. Roughly 80 to 90 percent of all respondents believe that they are safer than the typical individual for situations in which there is control over the risk. ${ }^{10}$ If individuals underassess the risks they face because of their control over the risk, then this would affect the interpretation of the results since the attractiveness of insurance is governed by the probabilities perceived by the insurance purchaser, not the probabilities stated in the survey.

Some of the articulation of the risk information in the survey also could lead to risk misperception. Scenario $2 \mathrm{a}$, for example, indicates that there will be a decrease in the child safety risk, but presumably this safety improvement would affect the safety of other passengers as well. How did respondents process this information?

If there is misperception of the risk information for whatever reason, then this bias not only affects the responses to particular questions, but also may contaminate the results elsewhere in the survey because of the chaining of the information in the survey structure. For example, if the stated probabilities are above the perceived probabilities, the survey will generate an underestimate of the implicit value of life in scenario 7a. The $\$ 1$ million value of life in that scenario is at the relatively low end of the value of life range in the literature. This bias, in turn, will lead to implicit risk assessments elsewhere in the survey that will be estimated as being too high.

The authors should recognize that choices under uncertainty-and particularly those involving low-probability events - tend to be fraught with various irrationalities. What one may be estimating in many cases is not the underlying preference individuals may have but rather the limitations on choices in highly complex situations.

10. See Viscusi and Magat (1987). 
One of the implied probabilities identified by the authors is that respondents act as if the perceived probability of death for a child who spends one month at a day camp is 1 in 1,500. This fatality risk in the day camp is roughly comparable to the annual accident risk faced by a worker in a high-risk construction job or that of a manufacturing worker during ten years of work on an assembly line.

Viewed somewhat differently, three months at a day camp would pose a fatality risk of 1 in 500. (One hesitates to estimate the risks associated with overnight camp.) If 30 million children were to spend their summers at a day camp, these estimates would imply that 60,000 would die. My own estimate, based primarily on parental observation, is that the risks perceived by the Calfee-Winston respondents are off by a factor of at least 1,000 .

This result highlights a major problem in dealing with low-probability events. Individuals have some difficulty with probability contexts of any kind, but it is especially difficult for them to make distinctions between risks of 1 in $1,000,1$ in 10,000 , or 1 in 100,000 , much less some of the refined distinctions that are pertinent to the risks associated with the types of events treated in the survey.

The result may be wildly inaccurate implications in terms of individual behavior. For example, in a study of bleach gassings from toilet bowl cleaner, Wesley Magat and I found that for risk reductions of 1 in $1,000,000$, the implied value of this health outcome was $\$ 1.78$ million dollars. For risk changes on the order of 15 in 10,000, the implied valuation of the health outcomes was $\$ 1,113 .{ }^{11}$ Changing the denominator of the risk question altered the implicit value of an injury by a factor of 1,000 . The major difficulty that individuals had in this case is that they tended to overestimate risks of low-probability events that are called to their attention.

More generally, we have very little experience in observing situations where we get a million draws from an urn to develop expertise in dealing with extremely low-probability events. Making any kind of decision with respect to such small risks is difficult, much less the types of difficult tasks that are imposed on the respondents by the Calfee and Winston survey questions.

11. These survey results and the sources of the difference are discussed in Viscusi (1992, chap. 4). 


\section{Valuing a Loss}

Any respondent attempting to assess the value of insurance coverage presumably needs to know the nature of the loss being insured. The survey could have been more detailed than it was in explaining the character of the loss. For example, scenario $6 \mathrm{a}$ indicates that the child will be handicapped at birth and must undergo several operations. In the words of the survey, this will make the child "quite unhappy." A child with an irritable stomach who needed burping might be characterized similarly. The cost to the parents and the effect on their lives of these operations are not discussed even though such health outcomes are likely to be disruptive and stressful.

The survey questions need more elaboration in other cases as well, such as the case of a crippling accident to the child in scenario $3 \mathrm{~b}$. Will there be any future income loss to the child? If so, insurance will become more attractive than if there were no income loss.

\section{Baseline Coverage}

To assess the desirability of insurance, it is essential for the survey to include information on the current life insurance, automobile insurance, medical insurance, and disability coverage of the respondent. Obtaining this information from the individuals who are surveyed would also enable them to think about the survey task and put the hypothetical insurance policies into context in terms of their own financial situations. Such questions consequently would be part of the attempt to create a market context that does not, in fact, exist.

A second purpose would be served by these questions. It is impossible to determine the desired level of pain and suffering coverage without knowing the existing coverage that an individual has for the various events discussed in the survey. For example, if an individual already has full insurance coverage, then all additional insurance is for pain and suffering, not simply the amount above replacement of the economic loss. In order to interpret correctly whether there is any desire to have pain and suffering insurance, one must know what insurance the individual already has.

For several of the scenarios, the survey, in effect, asked individuals to act as if certain classes of expenses were fully covered. More affluent respondents would know that many of the losses, such as disability 
effects, receive only partial coverage. Very poor respondents may not have any insurance and may not believe that any of these losses are covered. It would be useful to analyze the relationship of the amounts of current insurance coverage to the responses in an effort to ascertain the extent to which individuals adopted some of the hypothetical assumptions stated in the survey.

\section{Unclear Language}

Perhaps in part because the survey instruments were so numerous, they do not appear to have been sufficiently pretested to eliminate all situations of unclear language. Most readers of the Calfee and Winston paper will not encounter difficulties, but the more representative survey respondent may.

In some instances, such as scenarios $4 \mathrm{a}$ and $4 \mathrm{~b}$, in which an individual faces a complicated operation for a head injury, it is unclear what the purchase of the drug through the shots will achieve. This process is not made any easier for respondents by the presence of dominated alternatives. For example, in scenario $4 \mathrm{a}$, alternative 3 has the same side effects as alternative 2 with the same shots but at a different price. Alternative 6 costs more than alternative 2 even though there are no shots with alternative 6 and shots with alternative 2 . In this case the operation seemed to be the same, but the individual is given a $\$ 300$ discount if he receives the shots.

In scenarios $3 b$ and $4 b$, money is being paid out for income losses that is "in addition to payments for medical expenses." What exactly does this mean? Do all the options provide for medical expenses-even those such as package 1 , package 4 , package 6 , and package 9 in which there is no insurance payout of any kind? Is there any linkage between the insurance payout and the medical expenses payment?

There also seems to be a mismatch between the character of the injury and the nature of insurance. Scenario $7 \mathrm{~b}$ pertains to the risk of death from taking a vaccine, but the insurance payout is for "disability." It is also difficult to understand what that scenario means in terms of the degree of pain. Shots are rated as being "more painful" or "less painful."' Which hurts worse, the alternative 4 scenario with one shot that is "more painful," or the alternative 11 scenario in which there are three shots that are "less painful?"' More fundamentally, is this 
degree of pain likely to be of consequence? What does this degree of pain mean in absolute terms? There are no reference points given for respondents to put it in perspective.

\section{Conclusion}

Like many early forays into a survey area, this survey structure raises almost as many questions as it answers. Because of the difficulty of the subject matter and, in particular, the substantial problems individuals have in making decisions with respect to risky choices, I suggest that subsequent versions of this survey deal with a more limited set of options, make a better attempt to create a meaningful decision context, and recognize the limitations that individuals have when making complex choices under uncertainty.

If there is any greater single deficiency of this survey instrument, it is that it places such severe demands on respondents that they may be unable to give meaningful answers to the survey questions. These limitations arise in part because of the more general problems individuals have in making complex choices under uncertainty. These difficulties might not be as consequential in contexts where the choices involved were simpler.

Calfee and Winston have, however, embarked on a useful approach to ascertain the private value of insurance for pain and suffering compensation. This is an area in which the courts lack precise economic guidance. The optimal value of pain and suffering from the standpoint of deterrence is much better understood. The use of a survey methodology such as that introduced in this paper can potentially resolve the effect of injuries on the marginal utility of income and hence on the desirability of insurance. Whatever progress economists make in this area is likely to be the result of using surveys, such as this one, that create structured choice situations rather than rely on existing market data. The authors' overall research strategy of utilizing a survey approach is consequently quite sound and should provide the basis for future work on this difficult and important legal issue. 
Authors' Response: Viscusi does not provide a compelling reason to doubt the qualitative nature of our central result, which is that consumers are often willing to pay much more for prevention than for insurance, and that this disparity could cause strict liability for pain and suffering to involve a substantial deadweight loss to consumers. On a few important points, however, Viscusi's remarks could leave the reader with incorrect impressions.

The most fundamental misunderstanding pertains to the central goal of our research. This goal was to assess the disparity (if any) between consumers' willingness to pay for insurance versus prevention. From this perspective, a number of Viscusi's more trenchant observations are of decidedly less import, because even if they are correct, they apply more or less equally to assessments of both types of willingness to pay. Two examples are the misperception of probabilities (whether they be small or very small) and the use of simplifying decision heuristics. While one may doubt the precision of our estimates, there is little reason to think these cognitive difficulties caused us to estimate a substantial disparity in willingness to pay for insurance versus prevention, when such a disparity did not exist.

Two remaining points involve survey methods. The ranking task for respondents was not nearly so difficult as Viscusi portrays. As we explained in the paper, respondents were not asked directly to rank all thirteen or so packages. Rather, they assigned ratings along a willingness-to-purchase scale, and the complete ranking came at the end, when respondents placed the packages in order according to the scale, and resolved ties. This is a common procedure in market research for new products, and the details of our procedure were regarded as routine by the well-established market research firm that conducted the survey and assisted in survey design and pretesting.

Finally, we argue that by framing the choices so that consumers were aware only of the broad outlines of adverse events rather than the details of injuries and the many forms of pain and suffering that could arise, we improve validity. This approach is more faithful to the ways in which actual choices are made.

General Discussion: Robert Hall expressed surprise that the authors did not deal with the issue of incentives for avoiding human injury and death. He questioned the authors' assertion that adequate precautionary 
incentives could arise from reputational effects or regulation. He said that one reason why there are tort laws is because reputation and regulation are not always reliable and added that the United States is a much safer place than the rest of the world precisely because of its functioning tort system. Hall argued that, from a standpoint of incentives to protect people, the law actually provided for inadequate pecuniary damages. He noted that if a person is killed, damages are typically not awarded for all lost earnings, only for that portion that would have been received by a living claimant. As a result, the law does not recognize the fundamental efficiency value of protecting people as productive assets. Therefore, Hall claimed, there are probably insufficient existing incentives to protect human life.

He went on to say that from an economic standpoint, the goal of the tort system should be to impose upon a wrongdoer a full set of pecuniary and hedonic damages in order to get the right incentives to protect people, while at the same time eliminating or reducing the payout to victims and victims' relatives to avoid the excess insurance problem that the authors note in the paper. He agreed with the authors that reverse insurance, that is, the ability to sell in advance to a private institution one's right to bring a tort case against a wrongdoer, is the solution to the incentive and other problems with the current system that are identified in the paper. He noted, however, that such an arrangement is illegal under current law.

Roger Noll noted that the paper provided evidence on how people evaluate the various kinds of risk they face, but said that in his opinion, it did not address what actually happens in " 96.7 percent" of realworld cases, because it is important to know something about what kind of information is available to both buyer and seller, when they had access to the information, and how much heterogeneity there is in the world so that people can learn from other people's experiences.

Carl Shapiro noted that the authors' concept of deadweight loss is based upon the assumption that if an individual is hurt, that person has a low value of income, so any large sum given to him or her will have a low value, while any money awarded for an individual who is killed will be a complete social loss because that person has a "zero marginal utility of income." Shapiro said that such a viewpoint is unreasonable, because an individual does not have to spend all the money on himself or herself. Instead, money awarded as a result of an injury or death 
can be spent by the victim's relatives and friends. He suggested, therefore, that marginal utility of income would not drop off in actuality by as much as the survey results implied. Robert Hall pointed out, however, that the respondents took the ability to transfer compensation to others into account when they answered questions about how much they valued insurance.

George Borts disagreed with the analysis of deadweight loss presented in the paper. The price of a "risky" service includes an insurance provision to compensate accident victims. When such victims would not willingly purchase such insurance, a deadweight loss is supposed to occur, because there is too little consumption of the commodity that is generating the risk. Citing the cases of automobile and malpractice insurance, he disagreed that a reduction in consumption would actually occur in such a situation. He said that when automobile insurance is too costly, people will not buy it, but they will continue to drive. In addition, because medical costs are generally paid by third parties, it is not clear that consumers purchase fewer medical services simply because the price includes malpractice insurance.

Alvin Klevorick cautioned about the effects of a policy that would eliminate compensation for pain and suffering. He noted that Kip Viscusi had argued that juries that set pain and suffering awards often saw such awards as representing something additional, such as punitive damages, for example. Klevorick said that if damages for pain and suffering were abolished, juries might simply award such compensation under another guise. 


\section{References}

American Law Institute. 1991. Enterprise Responsibility for Personal Injury, Reporters' Study, Vol. I: The Institutional Framework and Vol. II: Approaches to Legal and Institutional Change. Philadelphia, $\mathrm{Pa}$.

Calfee, John E., and Paul H. Rubin. 1992. "Some Implications of Damage Payments for Nonpecuniary Losses." Journal of Legal Studies 21 (June): 371-411.

Croley, Steven P., and Jon D. Hanson. 1991. "What Liability Crisis? An Alternative Explanation for Recent Events in Products Liability.' Yale Journal on Regulation 8 (Winter): 1-111.

Evans, William, and W. Kip Viscusi. 1991. "Estimation of State-Dependent Utility Functions Using Survey Data.' Review of Economics and Statistics 73 (February): 94-104.

Horowitz, Michael, and Jeffrey O'Connell. 1992. “A Proposal to Expand Consumer Choice and Economic Opportunities by Deregulating the Auto Insurance Market.' Working paper. Manhattan Institute, Washington, D.C. September.

Litan, Robert, and Clifford Winston, eds. 1988. Liability: Perspectives and Policy. Washington, D.C.: Brookings.

Magat, Wesley A., and W. Kip Viscusi. 1992. Informational Approaches to Regulation. Cambridge, Mass.: MIT Press.

Magat, Wesley A., W. Kip Viscusi, and Joel Huber. 1992. "The Death of Risk Lottery Metric for Health Risks: Cancer and Nerve Disease." Working paper. Duke University, Department of Economics, Durham, N.C.

Miller, Ted R. 1989. “Willingness to Pay Comes of Age: Will the System Survive?" Northwestern University Law Review 83 (Summer): 876-907.

Priest, George L. 1991. "Can Absolute Manufacturer Liability Be Defended?" Yale Journal on Regulation 9 (Winter): 237-63.

Rubin, Paul H. 1993. Tort Reform by Contract. Washington, D.C.: American Enterprise Institute.

Rubin, Paul H., and John E. Calfee. 1992. "Consequences of Damage Awards for Hedonic and Other Nonpecuniary Losses." Journal of Forensic Economics 5 (Fall): 249-60.

Shavell, Steven. 1987. Economic Analysis of Accident Law. Cambridge, Mass.: Harvard University Press.

Viscusi, W. Kip. 1988. "Pain and Suffering in Product Liability Cases: Systematic Compensation or Capricious Awards?" International Review of Law and Economics 8 (December): 203-20.

- 1990. "The Value of Life: Has Voodoo Economics Come to the Courts?' Journal of Forensic Economics 3 (Fall): 1-15. 

versity Press.

1991. Reforming Products Liability. Cambridge, Mass.: Harvard Uni1992. Fatal Trade-offs: Public and Private Responsibilities for Risk. New York, N.Y.: Oxford University Press.

Viscusi, W. Kip, and Wesley A. Magat. 1987. Learning About Risk: Consumer and Worker Responses to Hazard Information. Cambridge, Mass.: Harvard University Press.

Viscusi, W. Kip, Wesley A. Magat, and Joel Huber. 1991. "Pricing Environmental Health Risks: Survey Assessments of Risk-Risk and Risk-Dollar Trade-offs for Chronic Bronchitis." Journal of Environmental Economics and Management, 21 (July): 32-51.

Viscusi, W. Kip, and William N. Evans. 1990. "Utility Functions that Depend on Health Status: Estimates and Economic Implications." American Economic Review 80 (June): 353-74.

Winston, Clifford, and Fred Mannering. 1984. "Consumer Demand for Automobile Safety." American Economic Review 74 (May): 316-19. 